NBER WORKING PAPER SERIES

\title{
RACIAL DISCRIMINATION AND HOUSING OUTCOMES IN THE UNITED STATES RENTAL MARKET
}

\author{
Peter Christensen \\ Ignacio Sarmiento-Barbieri \\ Christopher Timmins \\ Working Paper 29516 \\ http://www.nber.org/papers/w29516 \\ NATIONAL BUREAU OF ECONOMIC RESEARCH \\ 1050 Massachusetts Avenue \\ Cambridge, MA 02138 \\ November 2021
}

We thank students in the University of Illinois Big Data and Environmental Economics and Policy (BDEEP) Group and the Duke Environmental Justice Lab for research assistance. We acknowledge generous support from the National Science Foundation Economics Program and the Russell Sage Foundation Social, Political and Economic Inequality Program. All errors are our own. The views expressed herein are those of the authors and do not necessarily reflect the views of the National Bureau of Economic Research.

NBER working papers are circulated for discussion and comment purposes. They have not been peer-reviewed or been subject to the review by the NBER Board of Directors that accompanies official NBER publications.

(C) 2021 by Peter Christensen, Ignacio Sarmiento-Barbieri, and Christopher Timmins. All rights reserved. Short sections of text, not to exceed two paragraphs, may be quoted without explicit permission provided that full credit, including $\odot$ notice, is given to the source. 
Racial Discrimination and Housing Outcomes in the United States Rental Market Peter Christensen, Ignacio Sarmiento-Barbieri, and Christopher Timmins

NBER Working Paper No. 29516

November 2021

JEL No. J15,R31

\begin{abstract}
We report evidence on discriminatory behavior from the largest correspondence study conducted to date in the rental housing market. Using more than 25,000 interactions with rental property managers across the 50 largest U.S. cities, the study reveals that African American and Hispanic/ LatinX renters continue to face discriminatory constraints in the majority of U.S. cities although there are important regional differences. Stronger discriminatory constraints on renters of color (particularly African Americans) are also associated with higher levels of residential segregation and larger gaps in intergenerational income mobility. Using matched evidence on the actual rental outcomes at the properties in our experiment, we show that correspondence study measurements of discrimination do indeed predict actual outcomes.

Peter Christensen

Agriculture and Consumer Economics

University of Illinois at Urbana-Champaign

431 Mumford Hall

Urbana, IL 61801

pchrist@illinois.edu

Ignacio Sarmiento-Barbieri

Department of Economics

University of Los Andes

Calle 19A No. 1-37 Este Bloque W, Of. 821

Bogota, CU 111711

Colombia

i.sarmiento@uniandes.edu.co

\author{
Christopher Timmins \\ Department of Economics \\ Duke University \\ 209 Social Sciences Building \\ P.O. Box 90097 \\ Durham, NC 27708-0097 \\ and NBER \\ christopher.timmins@duke.edu
}




\section{Introduction}

Over the past decade, a range of studies have shown that racial discrimination continues to constrain the choices faced by minority households searching for high-quality housing $(1-4)$ and high-opportunity neighborhoods $(5,6)$. By limiting the access of certain groups to the beneficial effects of high amenity neighborhoods, discriminatory behavior may contribute to racial inequality through impacts on short-run, long-run and even intergenerational outcomes $(7-9)$.

The present study reports evidence from the largest correspondence experiment conducted to date in the housing market. Using a software bot developed at the National Center for Supercomputing Applications, the study examines more than 25,428 interactions between property managers and fictitious renters engaged in search on an online rental housing platform, revealing patterns of discrimination encountered in the initial stage of a search. The technology was designed to scale data collection and the execution of statistically powered experimental discrimination monitoring at low cost. The sampling strategy was designed to provide a direct comparison of the magnitude of discriminatory behavior across the 50 largest cities in the United States, allowing for a statistical ranking of the markets with the highest and lowest rates of discriminatory constraints.

While correspondence and audit experiments provide powerful evidence of disparate treatment in housing and other markets $(10)$, their key limitation is that the researcher never directly observes the effects of constraints faced by fictitious applicants on actual housing outcomes (11). The present study advances correspondence research by providing the first available evidence on the relationship between disparate treatment and subsequent rental housing outcomes by obtaining data on the renters that ultimately inhabit the properties sampled in the experiment. 


\section{Experimental Design}

The correspondence experiment used a computer bot that sent inquiries from fictitious renters to 8,476 property managers across the fifty largest metropolitan housing markets in the United States. Metropolitan housing markets were delineated using Core-Based Statistical Areas (CBSAs) as defined by the US Census. The sampling protocol was balanced across the 50 markets, such that rounds of experimental trials were conducted in unison. This balance ensures comparison of discriminatory constraints across different markets, avoiding conflation of regional differences with temporal (seasonal) variation.

The experiment targeted listings in downtown and suburban areas of each market on the day following the day on which each property was listed on the platform (see SM 1.1). For each listing, the bot then initiated a three day sequence of inquiries, sending one inquiry per day using fictitious identities drawn in random sequence from a set of 18 first/last name pairs that were selected to elicit cognitive associations with one of three racial/ethnic categories: African American, Hispanic/LatinX, and white. Property managers never received inquiries from two different identities on the same day. To account for the fact that names not only signal race but also other unobserved characteristics such as income $(12,13)$, the bot further stratified sampling of first names using maternal educational attainment and gender. Responses from property managers were registered as such if they were received within seven days and indicated that the property was available (See SM 1).

\section{Housing Discrimination in U.S. Cities}

We estimate the effects of racial bias on housing access using a linear probability model that limits identifying variation to within-property differences in behavior. Experimentally identified relative response rate differentials measure the difference in the probability of response to an 
inquiry from an African American or Hispanic/LatinX identity relative to the probability of response to a comparison white identity for the same listing (see SM 2). This measure divides the percentage point difference in the probability of a response for each of the groups of color by the baseline response rate to inquiries from white identities.

In the full sample, inquiries sent from white renter identities receive an average response rate of $60 \%$. We find that response rates to inquiries sent from African American and Hispanic/LatinX identities were 5.6 and 2.8 percentage points lower, respectively (Table SM2.1). These magnitudes imply a 54.4\% average response rate to inquiries sent from an African American identity and a $57.2 \%$ average response rate to to inquiries from Hispanic/LatinX identities to the same set of listings. They correspond to relative response rate differentials of $-9.3 \%$ for African American renters and $-4.6 \%$ lower for Hispanic/LatinX renters.

\section{The Geography of Discriminatory Behavior in the United States}

Overall differences in response rates mask important variation between and within regions of the United States. Figure 1 plots relative response rate differentials for the cities that we study with lines delineating the four major US regions defined by the Census. Inquiries sent from African American identities received response rates that were approximately 12\% lower (than response rates to comparison white identities) in the Midwest and in the Northeast, 7.9\% lower in the West, and 7.6\% lower in the South. Trials in the Midwest and South indicate a statistically significant difference in the level of discriminatory constraints facing African Americans in the two regions. Hispanic/LatinX renters faced stronger constrains in the Northeast $(8.1 \%)$, followed by the South and Midwest (5.2\% and 3.6\%) and then the West (2.6\%). The findings also indicate that African American renters face stronger constraints than Hispanic/LatinX renters in all regions, though the differences are only statistically significant in the Midwest and West. Estimates in Table SM3.1 show that these results are not significantly affected by COVID-19 
lockdowns or the effects of the murder of George Floyd and subsequent protests, both of which occurred during our sample period.

Our design provides a direct comparison of the magnitude of discriminatory behavior across the 50-city sample, allowing for a statistical ranking of the markets with the highest and lowest rates of discriminatory constraints (see Fig. SM3.2 for full ranking). We find the strongest discriminatory constraints facing African Americans in Chicago, IL, Los Angeles, CA, and Louisville, KY. We find the strongest constraints facing Hispanic/LatinX renters in Louisville, KY, Houston, TX, and Providence, RI. The experiment also reveals important differences in the markets characterized by strong discrimination against African American renters and those where Hispanic/LatinX renters face stronger constraints. We find that the statistical correlation between relative response rates between the two groups is relatively low $(\mathrm{R}=0.12)$ across the 50 cities, despite the fact that results are obtained from the the same set of properties. This provides evidence that the behavioral mechanisms that lead to stronger constraints facing one group may be group-specific and targeted, rather than related to a general proclivity to discriminate.

\section{Links to Neighborhood Segregation and the Income Mobility Gap}

Researchers have hypothesized that discriminatory behavior is more pronounced in segregated cities and may act as an underlying mechanism. Destination cities for African Americans leaving the south during the Great Migration, mainly in the Midwest and Northeast, had some of the highest rates of segregation (14). Researchers have described the process through which social norms and other exclusionary policies that emerged during this period continue to affect the magnitude of discrimination in housing markets $(15,16)$. Segregated cities are found to have systematically lower rates of school performance and lower wage rates (17).

Recent longitudinal evidence documents significant variation in the persistence of intergenerational income gaps across different neighborhoods in the United States (9). This research 
measures the incomes (at age 30) of African American, Hispanic/LatinX, and white children from 1978-1983 birth cohorts raised in the same neighborhoods by parents that fall in the same segment of the income distribution. The findings indicate that gaps in intergenerational income mobility are explained better by neighborhood-level than by household-level factors. While the authors find evidence of a strong correlation with measures of implicit racial bias, though they are not able to examine discriminatory behavior that may directly constrain housing choice.

Panel A of Figure 2 plots the relationship between discriminatory constraints and the level of residential segregation (as measured by the dissimilarity index) between households from each racial/ethnic group and the white comparison group in the 50 cities in the study. This geographic variation reveals a strong correlation between relative response rates and housing market segregation, illustrating that renters of color face stronger constraints in more segregated cities. In nearly all markets, both the level of segregation and the strength of discriminatory constraints is higher for African American-white households (circles) than for Hispanic/LatinXwhite households (triangles). Panel B plots the relationship between discriminatory constraints and intergenerational income mobility. Cities with larger gaps in African American-white income mobility also have higher levels of discriminatory behavior, though the same pattern does not hold for Hispanic/LatinX renters. The stark difference between the groups is important, given evidence that the African American-white income gap remains large in many parts of the country while the Hispanic/LatinX-white gap in incomes has fallen dramatically in the past generation (9).

\section{Discriminatory Constraints and Housing Outcomes}

A key limitation of the correspondence method is that the researcher never directly observes the effects of constraints faced by fictitious applicants on actual housing outcomes (11). However, recently-available data on the renter housing location choices provide an opportunity to link the 
listed rental properties sampled for the experiment to the racial/ethnic identities of households that subsequently rented them in 2020 ${ }^{1}$ Of the sample of properties in the correspondence experiment, $12 \%$ are ultimately rented by African American households, $11 \%$ by Hispanic/LatinX renters, $71 \%$ by white households, and the remaining $6 \%$ by households from other groups.

The merged data on response rates and housing outcomes allows us to test the hypothesis that discriminatory constraints identified in the experiment also predict market outcomes outside the experiment. If the explicit or implicit racial bias detected in the experiment (response/no response) affects access to a given property, then differences in response detected at the property level will also affect the likelihood that households from a given racial/ethnic group rent the property. We test for a statistical difference in the probability that a renter from a given racial/ethnic group ultimately rented a property when an inquiry from their group received a response, compared to no response. This test isolates the effect of experimental variation in response rates, controlling for differences in overall renter populations reported above.

Panel A of Figure 3 plots estimates of the probability that a household from a given racial/ethnic group rented a given property when an inquiry to that same property was denied a response in the experiment, relative to having received a positive response. Results in the top panel reveal that differential treatment identified in the correspondence study predicts differences in rental housing outcomes in the full sample. Non-response to a renter from a given racial/ethnic identity corresponds to a $26 \%$ reduction in the probability of a subsequent lease by a renter from the same group. Among renters of color, which includes African American and Hispanic/LatinX renters (23\% of the InfoUSA sample), non-response to an inquiry lowers the probability that a renter of color will ultimately inhabit a given property by $17.3 \%$. 2 The same general rela-

\footnotetext{
${ }^{1}$ InfoUSA's consumer database tracks 120 million households and 292 million individuals between 2006-2019. We impute the racial/ethnic identity of each renter in the InfoUSA dataset using the WRU algorithm, which computes the probability of a given name as corresponding to a racial/ethnic group using individuals' surnames and county of location $(18,19)$. See SM 5 for more details

${ }^{2}$ Illustraing the nonlinearity in the calculation of these effects, SM 5 explains why the full sample results de-
} 
tionship is found for each of the individual groups examined in the study, including the white comparison group. The rates for Hispanic/LatinX renters are not statistically significant in the full sample.

Estimates bottom panel illustrate even stronger relationships in census tracts where the renter's racial/ethnic group has lower representation. In this subset of properties, non-response to a renter of color corresponds to a $40.2 \%$ reduction in the probability of a subsequent lease by a renter of color. Whereas this relationship between non-response and renter outcomes do not predict statistically lower lease rates for Hispanic/LatinX and white renters in census tracts with above-median representation, they it is also true for African Americans in neighborhoods with above-median representation.

\section{Conclusion}

Housing discrimination can have a critical impact on residential location choices and access to opportunity. This paper provides experimental evidence on the incidence of discriminatory behavior across the 50 largest cities in the United States. Our design provides a direct comparison of the magnitude of discriminatory behavior across the 50-city sample, allowing for a statistical ranking of the markets with the highest and lowest rates of discriminatory constraints. Our results indicate that households of color face higher constraints when searching for rental properties in most U.S. markets. We find the strongest discriminatory constraints facing African Americans in Chicago, IL, Los Angeles, CA, and Louisville, KY. We find the strongest constraints facing Hispanic/LatinX renters in Louisville, KY, Houston, TX, and Providence, RI.

The present findings reveal a strong relationship between neighborhood segregation and racial discrimination in the rental market. This relationship disproportionately affects housing scribed in the top panel are not a simple average of the results conditioning upon race or upon race and racial/ethnic group representation in the lower panels. 
access for African American households due to stronger patterns of neighborhood segregation facing the African American community in most U.S. cities. This may help explain recent findings showing that residential segregation has contributed to amplifying income inequality (20), and the importance of city and neighborhood exposure in short, long and intergenerational outcomes (21-23). This study reveals evidence of a strong relationship between the income mobility gap and discriminatory constraints facing African American renters. Researchers have been unclear about the power of the correspondence design to predict difference in actual housing outcomes. The present study provides the first test of the relationship between experimental evidence of disparate treatment and subsequent differences in renter outcomes, revealing that discriminatory constraints provide important information about market behavior.

We cite several additional limitations of the correspondence design. First, our results are restricted to listings advertised on a single rental housing website. There is evidence that digital platforms are used to initiate the majority of rental housing search processes in the US. However, the study does not account for other channels or properties that may be advertised separately. Second, our estimates reflect the signal produced by a sample of names intended to elicit racialized perceptions. It is not representative of the total population of renters in the United States. Third, our results are limited to the first interaction between renters and landlords, and they do not capture discrimination in subsequent interactions. 


\section{References}

1. M. Ewens, B. Tomlin, L. C. Wang, Review of Economics and Statistics 96, 119 (2014).

2. M. Carlsson, S. Eriksson, Journal of Housing Economics 23, 41 (2014).

3. A. Hanson, Z. Hawley, Journal of Urban Economics 70, 99 (2011).

4. A. M. Ahmed, M. Hammarstedt, Journal of Urban Economics 64, 362 (2008).

5. P. Christensen, C. Timmins, NBER Working Paper No. w24826 (2018).

6. P. Christensen, I. Sarmiento-Barbieri, C. Timmins, NBER Working Paper No. w26805 (2020).

7. P. A. Akbar, S. Li, A. Shertzer, R. P. Walsh, Racial segregation in housing markets and the erosion of black wealth, National Bureau of Economic Research (2019).

8. B. S. Graham, Journal of Economic Literature 56, 450 (2018).

9. R. Chetty, N. Hendren, M. R. Jones, S. R. Porter, Race and Economic Opportunity in the United States: An Intergenerational Perspective, National Bureau of Economic Research, Working Paper No. w24441 (2018).

10. M. Bertrand, E. Duflo, Handbook of Economic Field Experiments (Elsevier, 2017), vol. 1, pp. 309-393.

11. J. J. Heckman, Journal of Economic Perspectives 12, 101 (1998).

12. J. Guryan, K. K. Charles, The Economic Journal 123 (2013).

13. R. G. Fryer Jr, S. D. Levitt, The Quarterly Journal of Economics 119, 767 (2004). 
14. D. Taylor, Toxic communities: Environmental racism, industrial pollution, and residential mobility (NYU Press, 2014).

15. R. Rothstein, The color of law: A forgotten history of how our government segregated America (Liveright Publishing, 2017).

16. N. Y. Li, Housing Market Channels of Segregation, Working Paper (2019).

17. L. P. Boustan, Racial residential segregation in american cities, Tech. rep., National Bureau of Economic Research (2013).

18. K. Khanna, K. Imai, wru: Who are You? Bayesian Prediction of Racial Category Using Surname and Geolocation (2021). R package version 0.1-12.

19. K. Imai, K. Khanna, Political Analysis pp. 263-272 (2016).

20. A. Fogli, V. Guerrieri, The end of the american dream? inequality and segregation in us cities, Tech. rep., National Bureau of Economic Research (2019).

21. R. Chetty, N. Hendren, L. F. Katz, American Economic Review 106, 855 (2016).

22. R. Chetty, N. Hendren, The Quarterly Journal of Economics 133, 1107 (2018).

23. R. Chetty, N. Hendren, The Quarterly Journal of Economics 133, 1163 (2018).

24. P. Christensen, I. Sarmiento-Barbieri, C. Timmins, AEA RCT Registry (2020).

25. V. Couture, J. Handbury, Urban Revival in America, 2000 to 2010, National Bureau of Economic Research, Working Paper No. w24084 (2017).

26. M. J. Holian, M. E. Kahn, et al., The impact of center city economic and cultural vibrancy on greenhouse gas emissions from transportation., Tech. rep., Mineta Transportation Institute (2012). 
27. S. M. Gaddis, Sociological Science 4, 469 (2017).

28. S. M. Gaddis, Socius 3, 1 (2017).

29. C. Crabtree, V. Chykina, Sociological Science 5, 21 (2018).

30. D. M. Cutler, E. L. Glaeser, J. L. Vigdor, Journal of Political Economy 107, 455 (1999).

Acknowledgments: The authors acknowledge generous support from the Russell Sage Foundation (Award: G-1258) and the National Science Foundation (Award: 185139). The authors have no competing interests to declare. We thank Christopher Kim, Daniel Rychel, Tom Phillips and student assistants in the University of Illinois Big Data and Environmental Economics and Policy (BDEEP) Group and the Duke Environmental Justice Lab for research assistance. All authors contributed equally to the study and names are listed alphabetically. The authors declare no conflicts of interest. All data and code will be available prior to publication using DOI. 


\section{Tables and Figures}

Figure 1. Relative Response Rates across the US
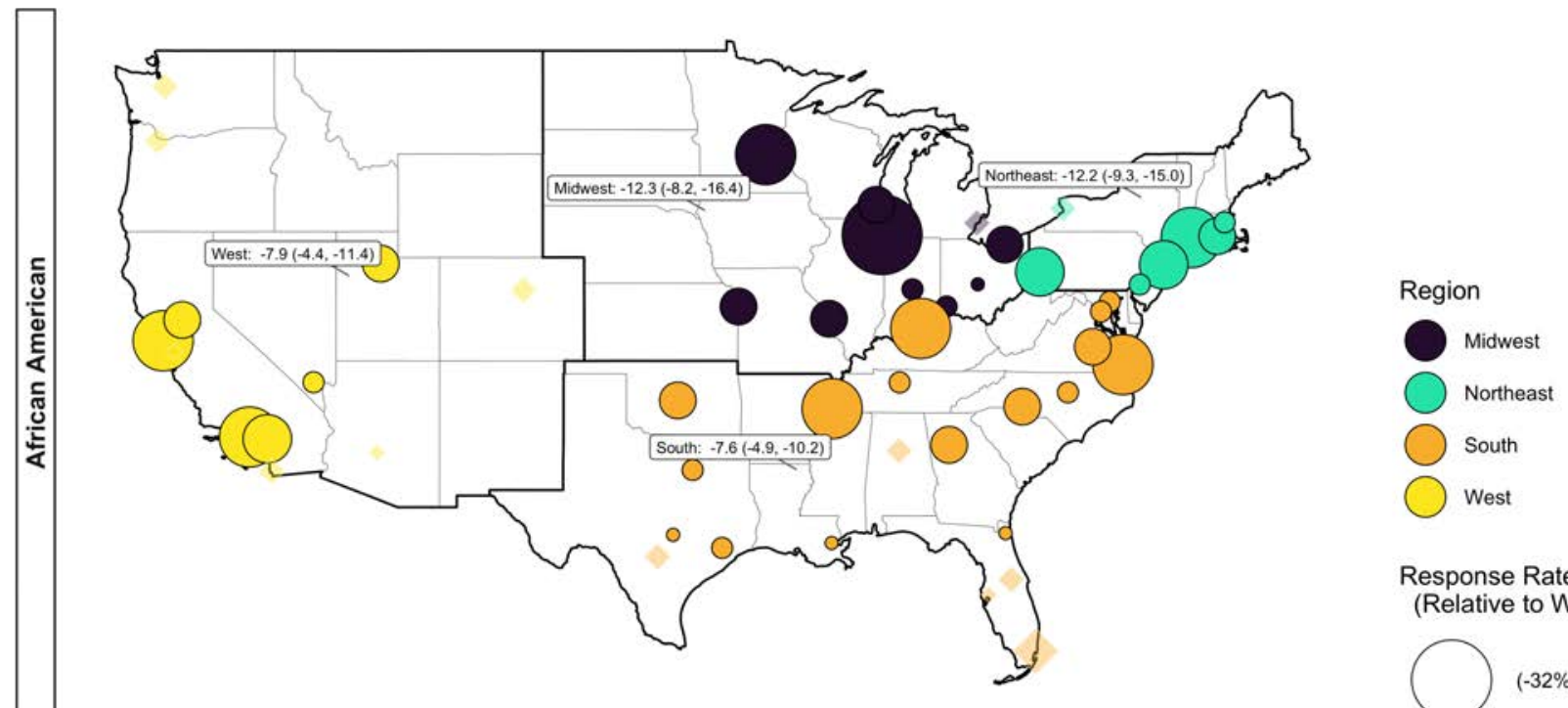

Response Rates (Relative to White Identities)

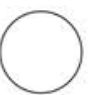

$(-32 \%,-29 \%]$
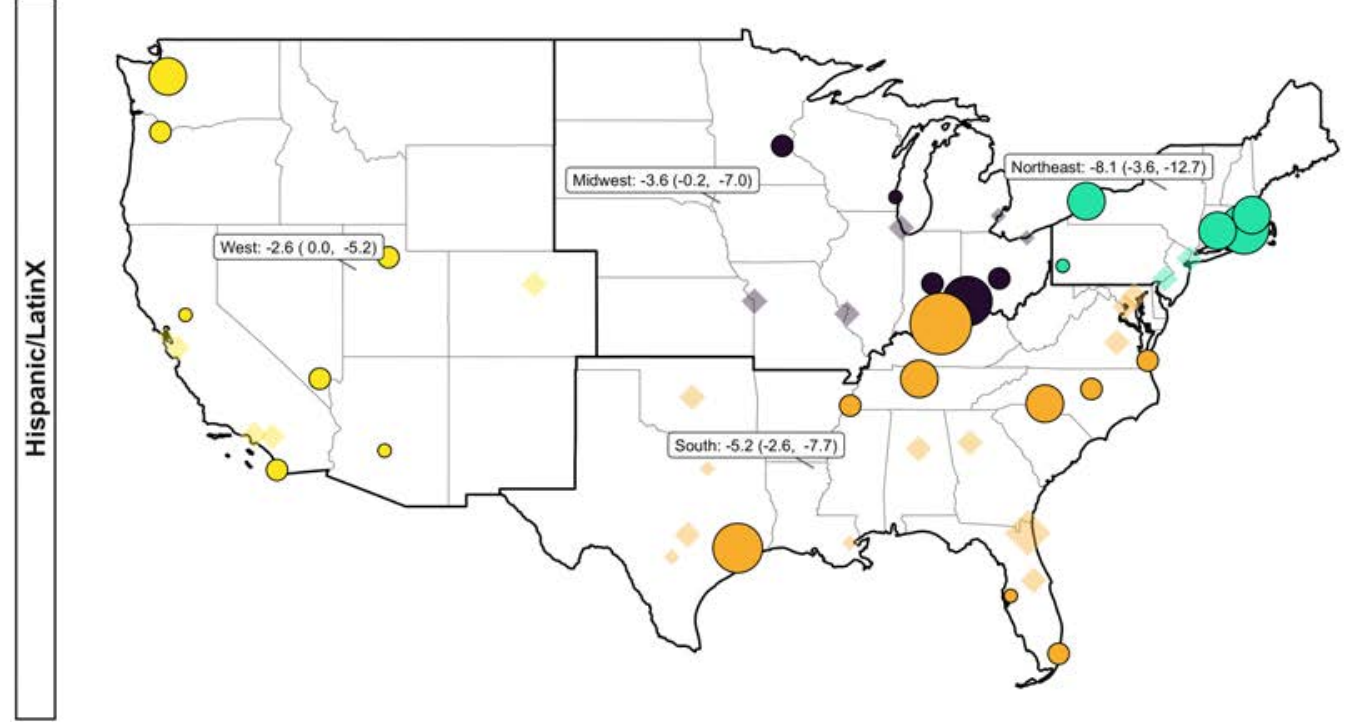

0

$(-29 \%,-20 \%]$<smiles>c1ccccc1</smiles>

$(-20 \%,-15 \%]$

(-15\%,-10\%]

$(-10 \%, 0 \%]$

- $>0 \%$

Statistically

$\bigcirc$ Significant

Not Significant

Note: Figure plots relative response rate differentials for the cities that we study with lines delineating the four major US regions defined by the Census. The top panel plots relative response rate differentials for African American identities relative to white identities, and Panel (B) for Hispanic/LatinX identities relative to white identities. Refer to Figure SM3.2 for the full set of point estimates and confidence intervals. All estimates are robust to inclusion/omission of controls. 
Figure 2. Relative Response Rates, Segregation, and Intergenerational Income Mobility

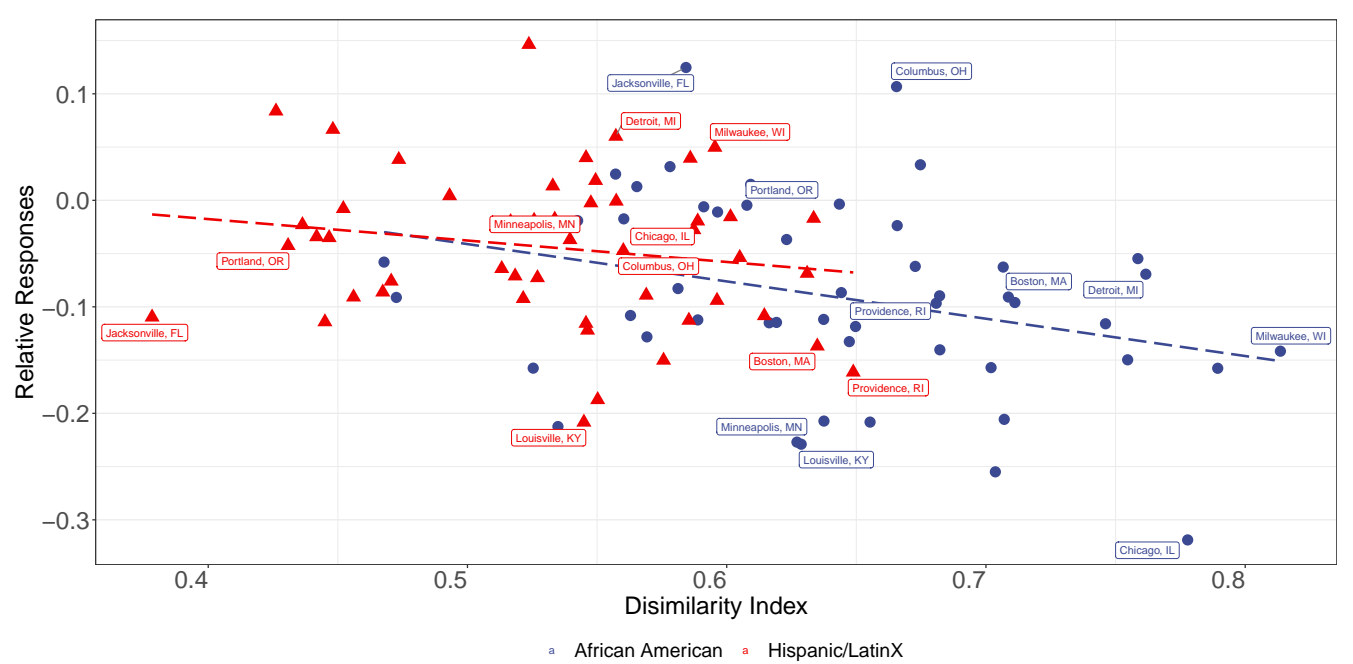

(a) Relative Response Rates by CBSA Dissimilarity Index

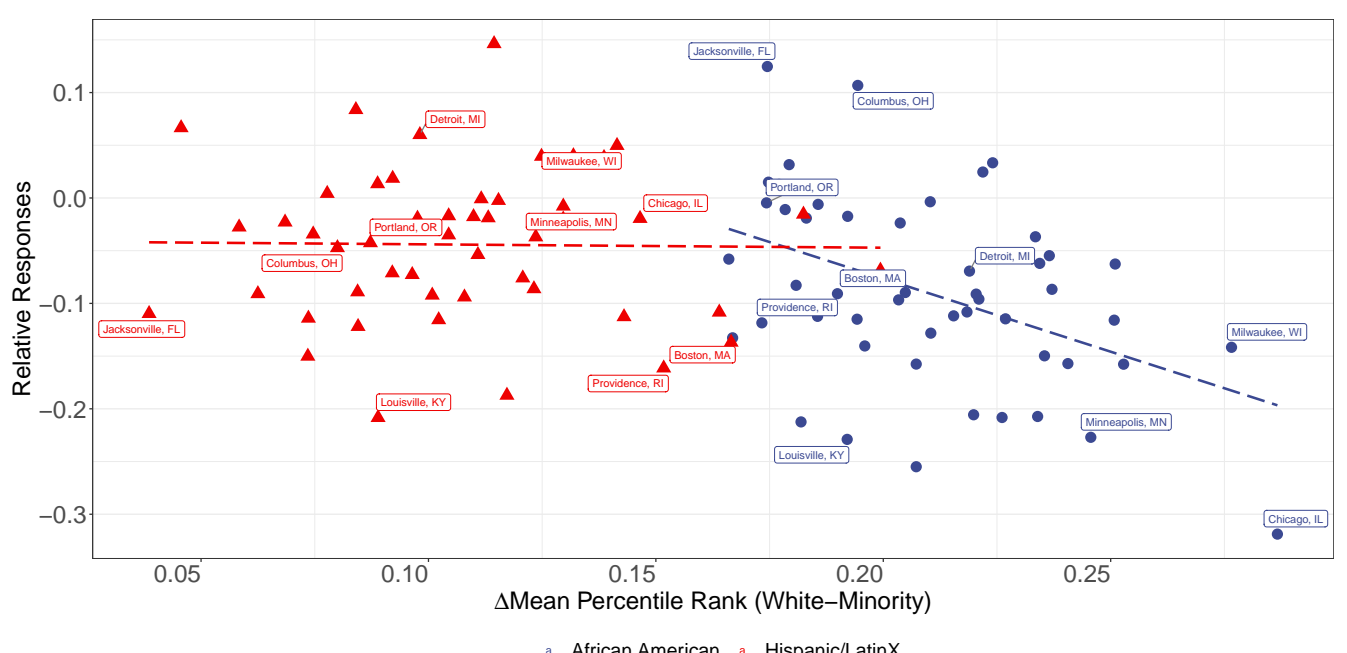

(b) Relative Response Rates by CBSA and Income Rank Gap

Note: Figure plots in both panels CBSA relative response rate differentials for African American and Hispanic/LatinX identities relative to white identities on the vertical axis. On the horizontal axis, Panel A plots the dissimilarity index for each CBSA between African Americans (circles) and Hispanic/LatinX (triangles) and whites. Panel B plots the relative response rate differentials and differences in income rank measured at parents' mean (21-23). Refer to Figure SM3.2 for the full set of point estimates and confidence intervals for relative response rates and $\mathrm{SM} 4$ for details on calculations of dissimilarity indices. 
Figure 3. Discriminatory Constraints and Housing Outcomes

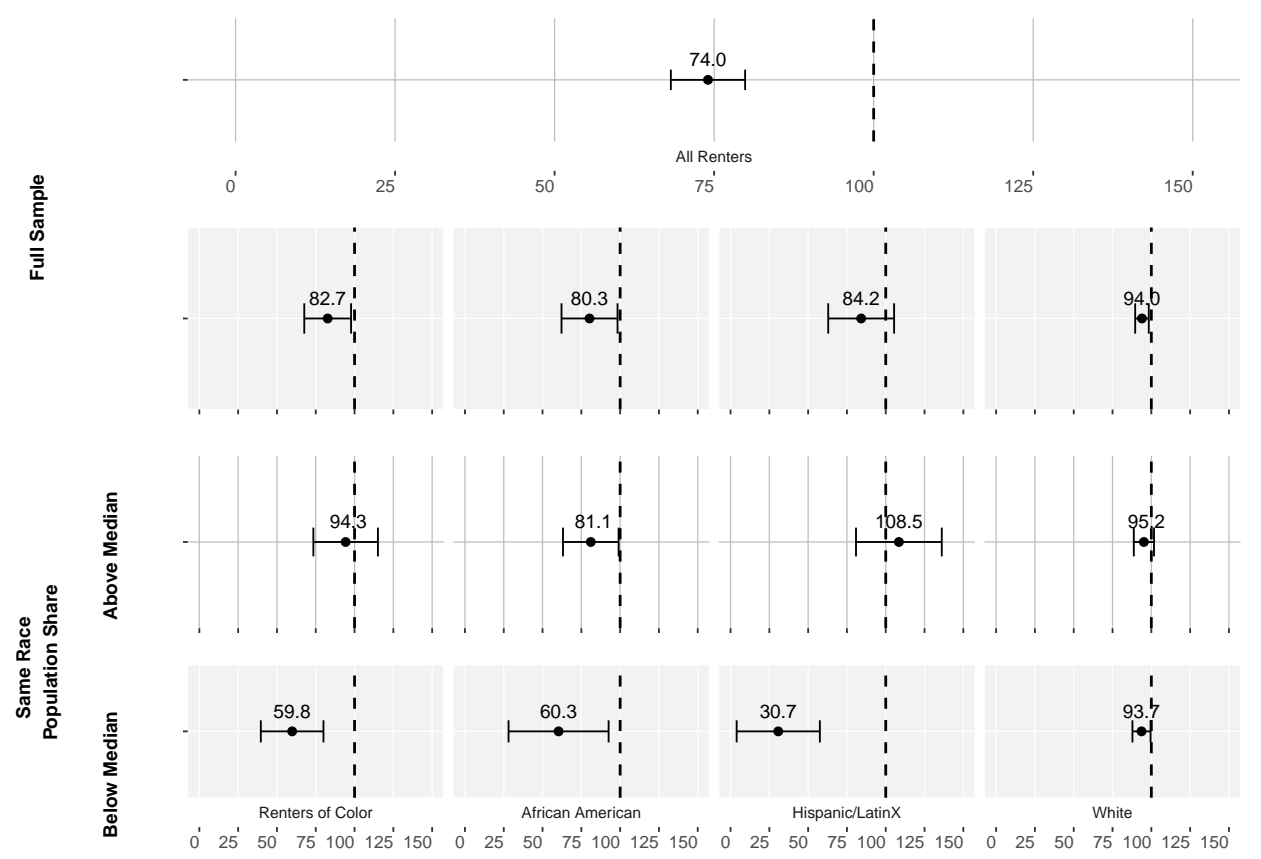

Note: Figure plots relative probabilities that a household from a given racial/ethnic group rented a given property when an inquiry to that same property was denied a response in the experiment, relative to having received a positive response. Whiskers denote $90 \%$ confidence intervals. Refer to SM 5 for estimation details 


\section{Supplementary Materials: \\ Racial Discrimination in the United States Rental Market}




\section{Methods Supporting Experimental Design}

The experiment was registered on the AEA RCT Registry as trial 5338 (24) and the human subjects protocol for this research design was approved by the University of Illinois Institutional Review Board (IRB \#18381) on 12/07/2017.

\subsection{Sampling Design}

The experiment was conducted in the fifty most populous Core-Based Statistical Areas (CBSAs) according to the 2010 US Census. Figure SM1.1 shows the location of the CBSAs in the experiment and Table SM1.1 describes their corresponding US Census Regions and Divisions. Rental listings were drawn using stratified-random sampling of downtown and suburban areas. Downtown zones were defined as the set of ZIP codes within a CBSA that contains the 5\% of the population nearest to the city center $(25,26)$. The research design simulates a housing search using available listings sampled simultaneously, such that the timing of the experiment was consistent across the 50 markets. In each sampling round, the bot randomly selected three listings from downtown zones and three from suburban zones of all cities in the sample that became active on the previous day. Then bot followed the listing for 21 days registering whether if the property was rented or not. 
Figure SM1.1. Core-Based Statistical Areas Statistical Areas in Study

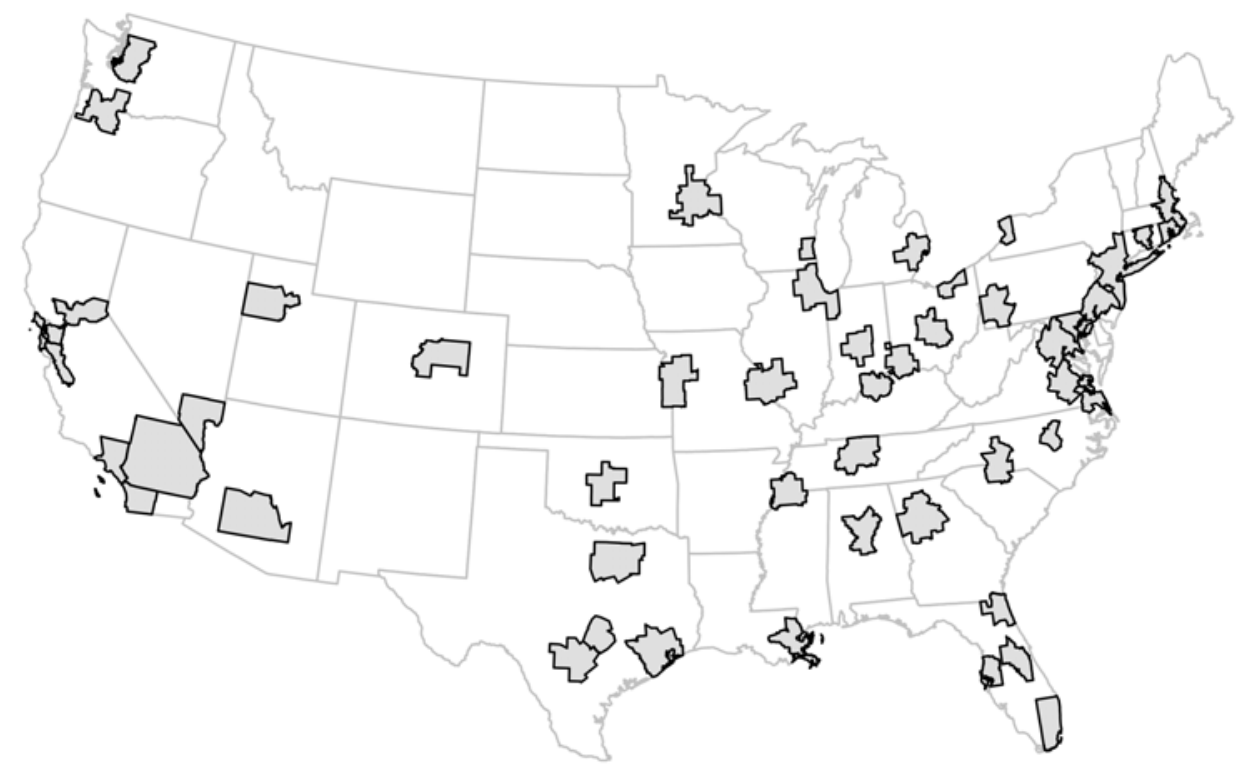

Note: Figure shows the location of the fifty most populated Core-Based Statistical Areas (CBSAs) where we conducted the experiment. 


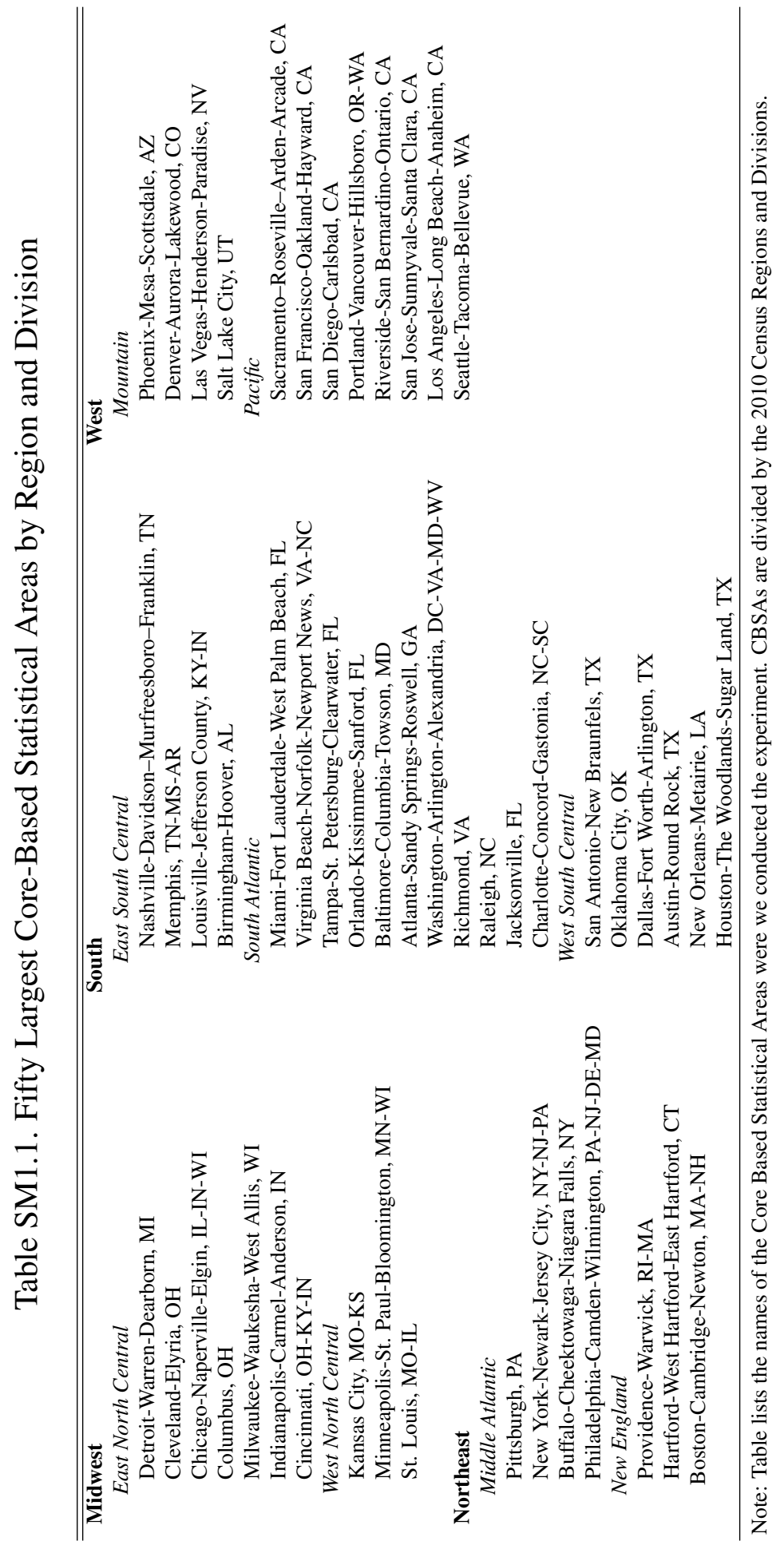




\section{Research Design: Inquiries}

The platform used in the present study transmits automated inquiries using standardized fillable forms, which has become the default for sending inquiries on many digital housing search platforms.

Figure SM1.2. Examplar Inquiry Form

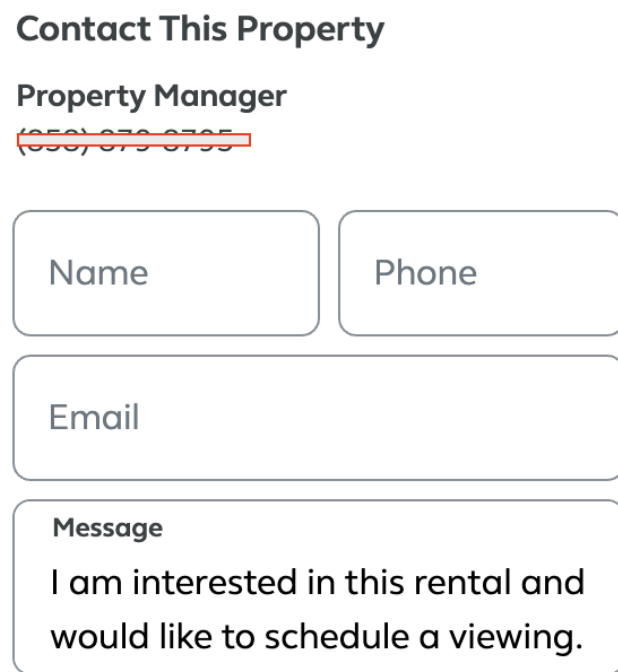

In the present study, inquiries are sent using the fillable form above, where prospective renters submit 3 pieces of information: (1) prospective renter's name, (2) prospective renter's phone number, (3) prospective renter's email address, (4) a message.

\section{Name}

1 of 16 randomly assigned first-last name pairs is assigned in any given inquiry (see SM Section 1.3 for details on name selection).

\section{Phone Number}

Each first-last name pair is associated with a single phone number. The full set of phone numbers comes from a small set of area codes associated with the NYC metro area, which is distinct 
from the metro areas in the sample. This is done to maximize the anonymity of identities in the study and reduce the likelihood of any differential signal extracted from specific area codes.

\section{Email}

Each first-last name pair is associated with a single gmail address. The full set of gmail addresses were constructed from first-last name pairs plus a series of randomly selected additional alphanumeric characters to guarantee availability.

\section{Message}

All inquiries were sent with the default message provided on the site: "I am interested in this rental and would like to schedule a viewing."

\section{Detection}

Correspondence studies rely on the assumption that online search tools will protect the anonymity of fictitious identities. We highlight the several features of the current design that were implemented to avoid detection:

1. Our study was implemented using communication (inquiries) through fillable forms on one of the largest housing search platforms in the United States. The forms do not rely on researcher-specified messages and provide 3 pieces of information to property managers: name, email, phone number. The use of default fillable forms allows a researcher to minimize potential salience effects from specific language used in researcher-formulated messages.

2. Inquiries sent to the same property were always sent at least 24 hours apart. In Table SM1.2, we compare the probability of responses obtained using the full sample with within-listing variation to the probability of responses obtained using only the sample of 
responses from the 1st inquiry made to a given listing, which are not statistically different from one another.

3. Different properties on the platform may be managed by same property manager, increasing the likelihood that a manager will receive multiple inquiries from the same identity. Since it is common for a given renter to send out multiple inquiries in the first stage of a housing search, this alone is unlikely to result in detection of the correspondence experiment. Consistent with other studies in the correspondence literature, we randomly assign inquiries from a set of 6 names per race/ethnic group, such that the probability that a property manager who is managing 2 simultaneous listings has a low probability of interacting with the same identity.

4. One concern that arises in both audit and correspondence studies is the potential for those being audited to check the online profile of the tester or fictitious applicant. Our correspondence design focuses on the first contact in a housing search, where the returns to learning about a respondent are low. We might expect online research to occur in later stages of contact.

5. Our study utilizes names that are sampled from the highest percentiles of the distribution of each of three racial groups. By construction, these very common names will be linked to many possible online identities. For example, if a property manager were to conduct a Google search of one of our fictitious identities, they would retrieve results like: this example. It is likely that a large fraction of the renter population also has a weak online presence. We assume that the likelihood that property managers will be affected by (the absence of) identifiable online information is low. 
Table SM1.2. Probability of Response. Within listing model and First Inquiry

\begin{tabular}{lcc}
\hline \hline & \multicolumn{2}{c}{$\begin{array}{c}\text { Dependent variable: } \\
\text { Response }\end{array}$} \\
\cline { 2 - 3 } & Full & First \\
& Sample & Inquiry \\
& $(1)$ & $(2)$ \\
\hline & & \\
African American & $-0.0561^{* * *}$ & $-0.0669^{* * *}$ \\
Hispanic/LatinX & $(0.0063)$ & $(0.0133)$ \\
& $-0.0277^{* * *}$ & $-0.0302^{* *}$ \\
Mean Response (White) & $(0.0057)$ & $(0.0133)$ \\
\hline Gender & & \\
Education Level & Yes & Yes \\
Inquiry Order & Yes & Yes \\
\hline Observations & 25428 & 8477 \\
\hline \hline
\end{tabular}

Notes: Table reports in column (1) coefficients from a within-property linear regression model including controls for gender, education and order the inquiry was sent. In column (2) from a linear model using only the sample of responses from the 1st inquiry made to a given listing. Standard errors clustered at the CBSA Downtown/Suburb level reported in parentheses.

* Significant at $10 \%$ level, ** significant at $5 \%$ level, *** significant at $1 \%$ level.

\subsection{Randomization and Response Coding}

After the listings were selected, a name was randomly drawn and assigned from three racial groups: African American, Hispanic/LatinX, and white. Therefore, each rental apartment received a series of three separate inquiries, one from each group, in three days, the duration of our experimental trial. The inquiry sequence from the different race groups was randomized, and inquiries for the same listing were never sent from two race groups on the same day. Thus our protocol followed the following order: (i) the bot identified all new listings in the downtown and suburban areas of each CBSA and selected three in each area (ii) It randomly sampled from the set of first - last name pairs; (iii) the bot sent an inquiry to the associated property manager; (iv) one day later, the bot randomly sampled from the set of 12 names that correspond to the remaining two racial identities and sent an inquiry; (v) on the third day, the bot sampled from the 6 names corresponding to the remaining racial identity and sent an inquiry. Table SM1.3 reports 
the results of balance tests. We find no systematic differences in responses by the order that the inquiries are sent out, the day of the week, the gender, or the maternal education associated to the name.

Table SM1.3. Overall Response Rates

\begin{tabular}{|c|c|c|c|c|c|}
\hline & (1) & (2) & (3) & (4) & (5) \\
\hline \multicolumn{6}{|c|}{ Panel A: Inquiry Order } \\
\hline & First & Second & Third & & \\
\hline \multirow[t]{2}{*}{ African American } & 0.0101 & -0.0073 & -0.0028 & & \\
\hline & $(0.0093)$ & $(0.0094)$ & $(0.0094)$ & & \\
\hline \multirow[t]{2}{*}{ Hispanic/LatinX } & 0.0074 & 0.0027 & -0.0100 & & \\
\hline & $(0.0094)$ & $(0.0094)$ & $(0.0093)$ & & \\
\hline \multicolumn{6}{|c|}{ Panel B: Evidence of Differential Choices by Weekday } \\
\hline & Mon & Tue & Wed & Thurs & Fri \\
\hline \multirow[t]{2}{*}{ African American } & -0.0011 & -0.0015 & -0.0013 & 0.0021 & -0.0011 \\
\hline & $(0.0058)$ & $(0.0052)$ & $(0.0063)$ & $(0.0053)$ & $(0.0062)$ \\
\hline \multirow[t]{2}{*}{ Hispanic/LatinX } & 0.0000 & 0.0017 & 0.0002 & -0.0004 & 0.0012 \\
\hline & $(0.0056)$ & $(0.0055)$ & $(0.0063)$ & $(0.0053)$ & $(0.0055)$ \\
\hline \multicolumn{6}{|c|}{ Panel C: Gender and Mother's Education Level } \\
\hline & \multicolumn{2}{|c|}{ Gender } & \multicolumn{3}{|c|}{ Mother's Education } \\
\hline & Male & Female & Low & Medium & High \\
\hline \multirow[t]{2}{*}{ African American } & -0.0006 & 0.0006 & -0.0073 & 0.0024 & 0.0049 \\
\hline & $(0.0080)$ & $(0.0080)$ & $(0.0075)$ & $(0.0072)$ & $(0.0070)$ \\
\hline \multirow[t]{2}{*}{ Hispanic/LatinX } & -0.0027 & 0.0027 & -0.0050 & 0.0016 & 0.0035 \\
\hline & $(0.0076)$ & $(0.0076)$ & $(0.0072)$ & $(0.0071)$ & $(0.0079)$ \\
\hline Mean Response (White) & 0.60 & 0.60 & 0.60 & 0.60 & 0.60 \\
\hline Observations & 25,428 & 25,428 & 25,428 & 25,428 & 25,428 \\
\hline
\end{tabular}

Notes: Table reports coefficients from a within-property linear model including controls on different outcomes. In Panel A, the dependent variable takes 1 or 0 depending the order in which the inquiry was sent out, i.e. in Column (1) takes 1 if the inquiry was sent first and 0 otherwise. Regressions in Panel A include controls for gender and education level. In Panel B, takes 1 or 0 depending the weekday the inquiry was sent and includes control for gender, education and order the inquiry was sent. Panel C, does the same for male and females, and levels of maternal education. In the first case, it includes control for education and order the inquiry was sent. In the second case, it controls for gender and order the inquiry was sent. Standard errors clustered at the CBSA Downtown/Suburb level.

* Significant at $10 \%$ level, ** significant at $5 \%$ level, *** significant at $1 \%$ level.

Responses from property managers were received via email (Gmail address associated with each name), phone messages (individual phone numbers associated with each name), and text messages. The content of phone, text, and email responses from property managers are recorded 
by a team of human coders to ensure the quality of the data. A positive response is coded as such if it is received within 7 days and it indicates that the property is available for rent. Figure SM1.3 plots the distribution of inquiry response time in the sample: $55 \%$ of responses are received within the first 8 hours of an inquiry, $80 \%$ are received within 24 hours and $98 \%$ are received within 5 days. The 7-day cutoff is used to restrict responses that may be received weeks or months after an inquiry and are not counted as choices in the study.

Figure SM1.3. Days between Inquiry and Response

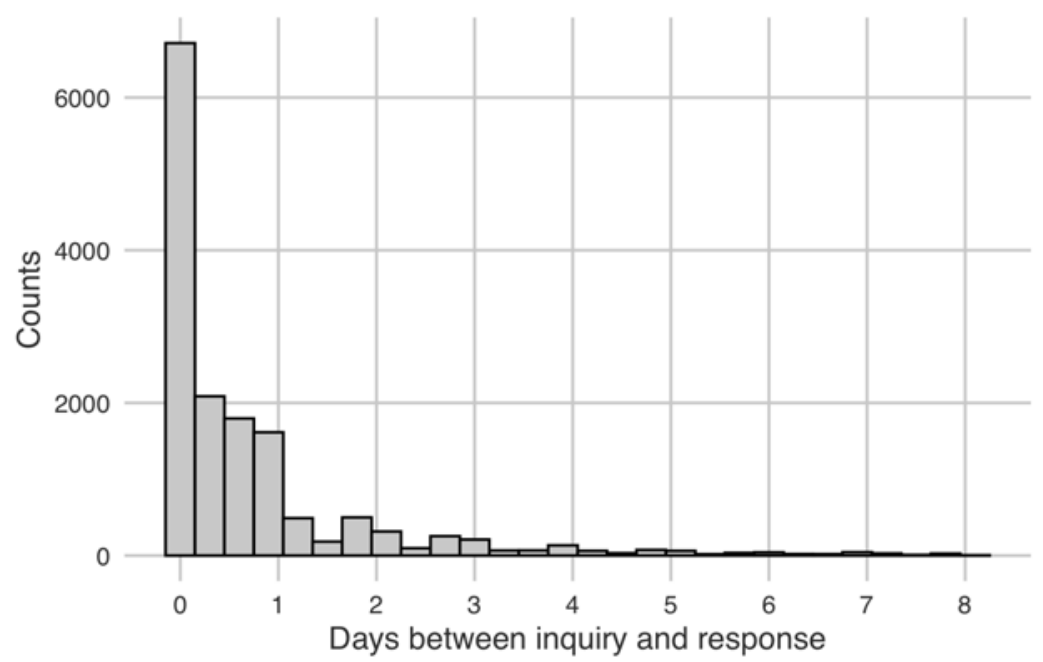

Note: Figure plots times elapsed between inquiries and responses in the sample using the timestamp given at the moment that an inquiry is sent and the timestamp given on the phone, email, or text response.

\subsection{Name Selection}

In correspondence studies, the researcher "corresponds" with the subject using fictitious identities. These fictitious identities are identical in every way except that they vary on a single trait (10). The correspondence between the researcher and the subject is conducted either by mail or online platforms. The researcher sends applications to rent a home, find a job, etc. Differences in responses are generally taken as evidence o discrimination. 
In this study, we vary names as the trait that elicits differential responses. An essential step is selecting names that are more likely to elicit the desired behavior while holding everything else constant. This study constructs first and last names pairs that have been shown to elicit racialized associations with each of 3 racial/ethnic categories: African American, Hispanic/LatinX, and White $(27,28)$

The first names used have a high congruence with the statistical distribution based on birth records and external classification by survey responders $(27,28)$. Furthermore, the birth record data used to construct the names cover the years 1994 to 2012, making them relevant for renters under age 25 as of the time of our study (27). Panel A of Table SM1.4 reports the identification rates for the specific subset of first names that we use in the present study $(27,28)$. Last names were generated using the distribution from the 2010 census. Panel B shows the set of last names used. In each case, identification rates increase with the inclusion of matched last names. The final set of first-last name pairs that we use are: Nia Harris, Jalen Jackson, Ebony James, Lamar Williams, Shanice Thomas, DaQuan Robinson, Isabella Lopez, Jorge Rodriguez, Mariana Morales, Pedro Sanchez, Jimena Ramirez, Luis Torres, Aubrey Murphy, Caleb Peterson, Erica Cox, Charlie Myers, Leslie Wood, Ronnie Miller. 
Table SM1.4. Identification Rates for First Names and Last Name Frequencies

\begin{tabular}{|c|c|c|c|c|}
\hline \multicolumn{5}{|c|}{ Panel A. Identification Rates $(27,28)(\%)$} \\
\hline Race & $\begin{array}{l}\text { First } \\
\text { Name }\end{array}$ & $\begin{array}{c}\text { No } \\
\text { Last Name }\end{array}$ & $\begin{array}{l}\text { Last Name } \\
\text { Included }\end{array}$ & $\begin{array}{c}\text { Tercile } \\
\text { Mother's Education }\end{array}$ \\
\hline African American & $\mathrm{Nia}$ & 41 & 65 & High \\
\hline African American & Jalen & 63 & 71 & High \\
\hline African American & Ebony & 91 & 95 & Med \\
\hline African American & Lamar & 88 & 94 & Med \\
\hline African American & Shanice & 93 & 92 & Low \\
\hline African American & DaQuan & 91 & 96 & Low \\
\hline Hispanic/LatinX & Isabella & 48 & 98 & High \\
\hline Hispanic/LatinX & Jorge & 86 & 98 & High \\
\hline Hispanic/LatinX & Mariana & 78 & 99 & Med \\
\hline Hispanic/LatinX & Pedro & 98 & 99 & Med \\
\hline Hispanic/LatinX & Jimena & 49 & 97 & Low \\
\hline Hispanic/LatinX & Luis & 83 & 99 & Low \\
\hline White & Aubrey & 90 & 93 & High \\
\hline White & Caleb & 77 & 84 & High \\
\hline White & Erica & 82 & 93 & Med \\
\hline White & Charlie & 86 & 91 & Med \\
\hline White & Leslie & 72 & 93 & Low \\
\hline White & Ronnie & 71 & 89 & Low \\
\hline \multicolumn{5}{|c|}{ Panel B. Last Names Frequency of Occurrence in 2010 Census (\%) } \\
\hline Race & Last Name & African American & Hispanic/LatinX & White \\
\hline African American & Harris & 42.4 & 2.3 & 51.4 \\
\hline African American & Jackson & 53.0 & 2.5 & 39.9 \\
\hline African American & James & 38.9 & 3.1 & 51.6 \\
\hline African American & Williams & 47.7 & 2.5 & 45.8 \\
\hline African American & Thomas & 38.8 & 2.5 & 52.6 \\
\hline African American & Robinson & 44.9 & 2.6 & 48.7 \\
\hline Hispanic/LatinX & Lopez & 0.6 & 92.9 & 4.9 \\
\hline Hispanic/LatinX & Rodriguez & 0.5 & 93.8 & 4.8 \\
\hline Hispanic/LatinX & Morales & 0.6 & 93.2 & 4.6 \\
\hline Hispanic/LatinX & Sanchez & 0.5 & 93.0 & 5.0 \\
\hline Hispanic/LatinX & Ramirez & 0.3 & 94.5 & 3.9 \\
\hline Hispanic/LatinX & Torres & 0.6 & 92.2 & 5.4 \\
\hline White & Murphy & 11.5 & 2.3 & 83.1 \\
\hline White & Peterson & 10.1 & 2.4 & 84.4 \\
\hline White & Cox & 12.1 & 2.3 & 82.6 \\
\hline White & Myers & 10.5 & 2.1 & 84.5 \\
\hline White & Wood & 5.6 & 2.4 & 88.7 \\
\hline White & Miller & 10.8 & 2.2 & 84.1 \\
\hline
\end{tabular}

Notes: In Panel A, table shows identification rates for the first names that we used in our study, if the names are presented without and with a last name, and the average tercile of the mother's education $(27,28)$. In Panel B, table shows the last names used withe the frequency of occurrence by race/ethnicity. In the study, we use the following first-last name pairs; Nia Harris, Jalen Jackson, Ebony James, Lamar Williams, Shanice Thomas, DaQuan Robinson, Isabella Lopez, Jorge Rodriguez, Mariana Morales, Pedro Sanchez, Jimena Ramirez, Luis Torres, Aubrey Murphy, Caleb Peterson, Erica Cox, Charlie Myers, Leslie Wood, Ronnie Miller.

It is worth noting that these names may not be representative of the entire population's names. However, they are chosen because there is strong empirical support of the alignment between these names and associated racial/ethnic perception (27-29). 
A potential concern is that the tested subjects can potentially check online the auditor's profile. This study assumes that these online checks will not affect the results. This assumption in our setting is likely to hold because: (i) we restrict the focus on the first contact. It is unlikely that the subject is searching for the applicant since returns are low at this stage. (ii) the names chosen in this study are prevalent. Thus they are linked to many possible online identities. Furthermore, this study assumes that response probabilities are not affected by our chosen identities' online presence. 


\section{Methods for Estimating Relative Response Rate Differen- tials}

The experimental design involves a sequence of binomial decisions $(j)$, where the property manager of a given listing $i$ decides whether to respond $\left(\right.$ Response $\left._{i j}=1\right)$ or not $\left(y_{i j}=0\right)$ with $j=1,2,3$. The magnitude of discriminatory constraints are estimated using a within-listing linear probability model:

$$
\text { Response }_{i j}=\beta_{A} \text { African American } \text { Af }_{j}+\beta_{L} \text { Hispanic/Latin }_{j}+\theta X_{j}+\delta_{i}+\epsilon_{i j}
$$

African American ${ }_{j}$ and Hispanic/Latin $X_{j}$ are indicator variables that take a value of one if the race group associated with the identity is either African American or Hispanic/LatinX; and zero otherwise. $X_{j}$ is a vector of identity-specific control variables: gender, education level, and the order in which the inquiry was sent. Given that names are drawn randomly and balanced across gender, education level, and inquiry order, estimates of $\beta$ should be robust to the inclusion/omission of $X_{j}$.

\section{Average Effects and Robustness to Controls}

Table SM2.1 reports estimates from Eq. 1 from specifications including different sets of controls. Estimates are robust across specification. Specifications including controls have slightly higher precision. $\delta_{i}$ is a landlord-property specific fixed effect, that controls from any within landlord-property time invariant characteristics. By generating within-property estimates of response for each racial group, we can more directly examine the effect of discriminatory constraints on each choice set in the sample. The $\beta$ coefficients measure the within-listing difference in the probability of a response to an inquiry from an African American or Hispanic/LatinX identity relative to a comparison white identity. The estimate of -0.0561 in Table SM2.1 implies that the probability of response to the average inquiry from an African American identity 
is $5.6 \%$ lower than a comparison white identity in the full sample. The probability of response to the average inquiry from a Hispanic/LatinX identity is $2.7 \%$ lower than a comparison white identity in the full sample.

Table SM2.1. Estimates of Discriminatory Constraint on Housing Choice: Robustness to Controls

\begin{tabular}{lcccc}
\hline \hline & \multicolumn{4}{c}{ Dependent variable: Response } \\
\cline { 2 - 5 } & $(1)$ & $(2)$ & $(3)$ & $(4)$ \\
\hline African American & $-0.0558^{* * *}$ & $-0.0558^{* * *}$ & $-0.0558^{* * *}$ & $-0.0561 * * *$ \\
& $(0.0062)$ & $(0.0062)$ & $(0.0063)$ & $(0.0063)$ \\
Hispanic/LatinX & $-0.0272^{* * *}$ & $-0.0273 * * *$ & $-0.0272^{* * *}$ & $-0.0277 * * *$ \\
& $(0.0057)$ & $(0.0058)$ & $(0.0058)$ & $(0.0057)$ \\
\hline Mean Response (White) & 0.60 & 0.60 & 0.60 & 0.60 \\
\hline Gender & & Yes & Yes & Yes \\
Education Level & & & Yes & Yes \\
Inquiry Order & 25,428 & 25,428 & 25,428 & 25,428 \\
\hline Observations & & & & Yes \\
\hline \hline
\end{tabular}

Notes: Table reports coefficients from a within-property linear regression model. Columns include successively more controls for gender, education, and inquiry order.

* Significant at $10 \%$ level, ** significant at $5 \%$ level, $* * *$ significant at $1 \%$ level.

In the main text, we express the coefficients in equation (1) as relative response rates, which compare the probability of a response to an inquiry from a given group to the probability for the white group. We calculate relative response rates using the following equations:

$$
\begin{gathered}
R R_{A}=\frac{P(\text { Response } \mid \text { Af } A m=1)}{P(\text { Response } \mid W=1)}=\frac{\beta_{A}}{\mu_{W}} \\
R R_{L}=\frac{P(\text { Response } \mid \text { Latin } X=1)}{P(\text { Response } \mid W=1)}=\frac{\beta_{L}}{\mu_{W}}
\end{gathered}
$$

where $\mu_{W}$ is the average response for whites. Standard errors for relative response rates are obtained using the delta method. 


\section{Methods for Relative Response Rates by City and Region}

In this section, we first provide detailed documentation of the cross-city variation in baseline (white) response rates and response rates by race group underlying the variation observed in Figure 1. Next, we examine the correlation between African American and Hispanic/LatinX relative response rates across cities and regions, and then document the correlation between relative response rates and baseline rates.

We then measure the robustness of our estimates to the inclusion/omission of experimental trials conducted during major events occurring during the study period, including (1) the onset of lockdowns during the early part of COVID-19 and (2) the murder of George Floyd and subsequent protests. We do not find evidence of systematic differences during these periods. Finally, we test for heterogeneity in relative response rates across the urban/suburban divide. We do not find evidence of differences in relative response rates in housing options located in downtown versus suburban zones in our 50 city sample.

\section{Overall and Relative Response Rates by City}

We begin by reporting average response rates and estimates of relative response rates across each of the 50 markets in our sample. Figure SM3.1 plots the average response rates to inquiries from white identities across all rounds conducted in each market. We find substantial heterogeneity in these baseline response rates across the 50 housing markets, ranging from $42 \%$ in Las Vegas, NV to $76 \%$ in Denver, CO. Baseline rates in 37 of the 50 city sample fall between $50-70 \%$. 
Figure SM3.1. Average Response Rates by CBSAs for White Identities

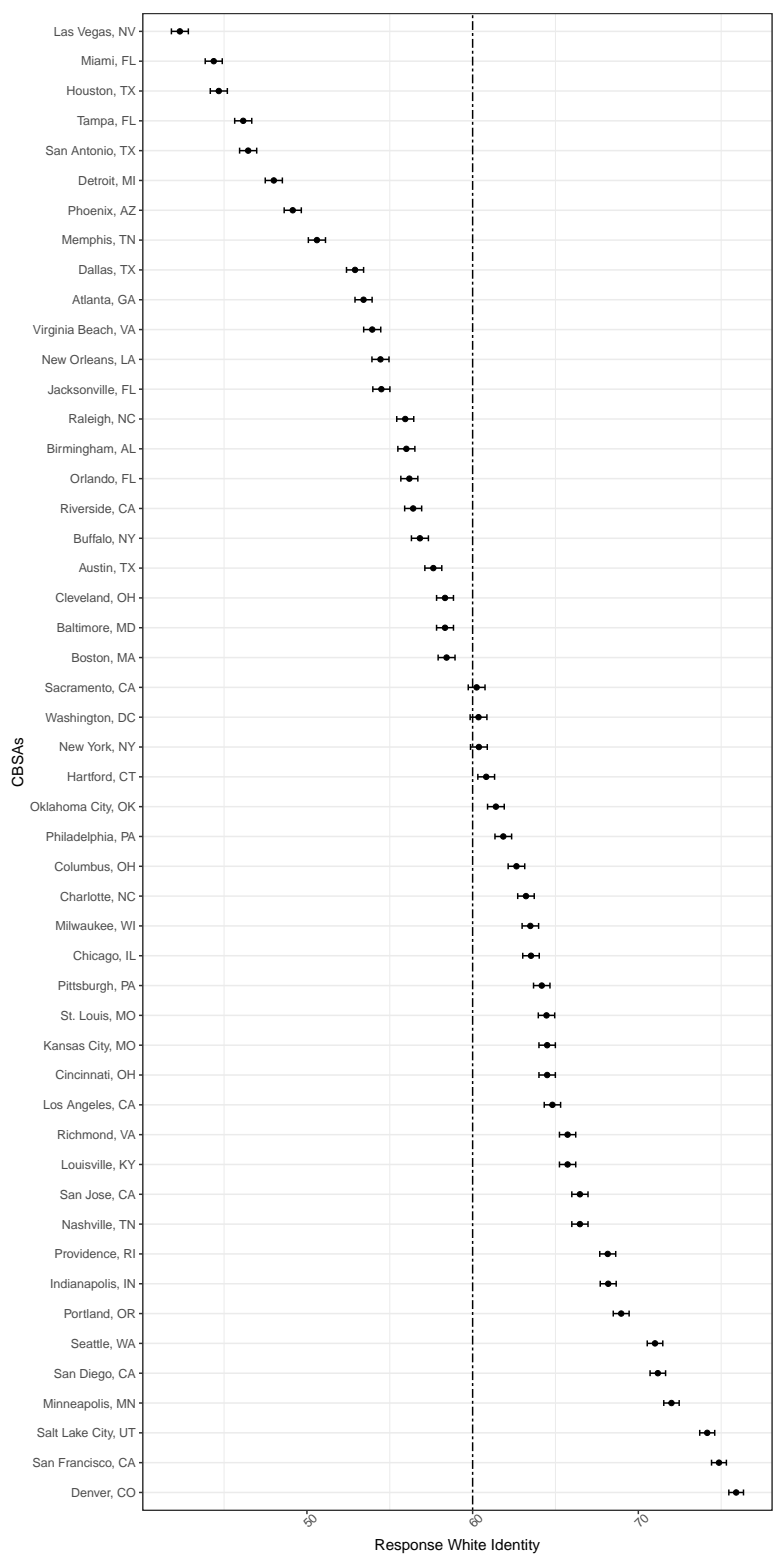

Note: Figure illustrates average response rates for the white identity. Whiskers denote $90 \%$ confidence intervals. Dashed line is the average for all the CBSAs.

Figure SM3.2 plots the relative response rates to African American and Hispanic/LatinX identities across all rounds conducted in each of the 50 markets. We find substantial heterogeneity in relative response rate differentials for both groups. Relative response rate differentials with 
respect to inquiries sent from African American identities range from $-36 \%$ in Chicago, IL to $6 \%$ in Jacksonville, FL. Relative response rate differentials with respect to inquiries sent from Hispanic/LatinX identities range from $-21 \%$ in Louisville, KY to $14 \%$ in Phoenix, AZ.

Figure SM3.2. Relative Response Rate Differentials by CBSAs

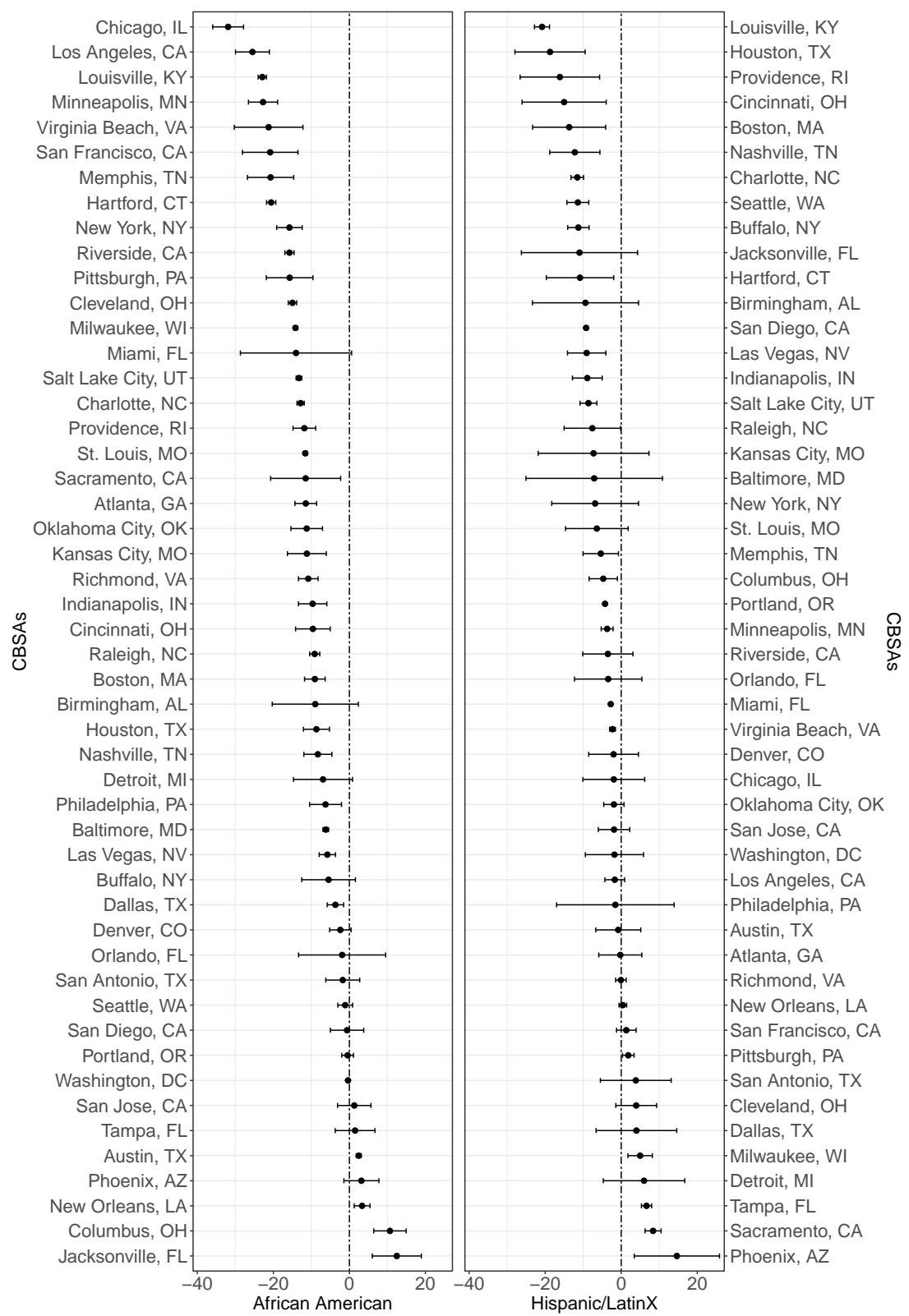

Note: Figure plots the relative response rates to African American (left) and Hispanic/LatinX (right) identities across all rounds conducted in each of the 50 markets. Whiskers denote $90 \%$ confidence intervals. 
Next, we investigate whether African American and Hispanic/LatinX identities tend to experience similar relative response rates (high or low) in individual markets and regions of the country. If relative response rate differentials are highly correlated between those two groups, then our results may be better interpreted as evidence of broader discrimination against people of color more generally, rather than discrimination that is targeted at particular groups. Figure SM3.3 plots the correlation between relative response rate differentials for African American and Hispanic/LatinX identities in all markets (Panel A) and by Census Region (Panel B). We do not any find evidence of strong correlations between discriminatory constraints facing these two groups across all markets or within regions.

Figure SM3.3. Correlation Between Relative Response Rate Differentials

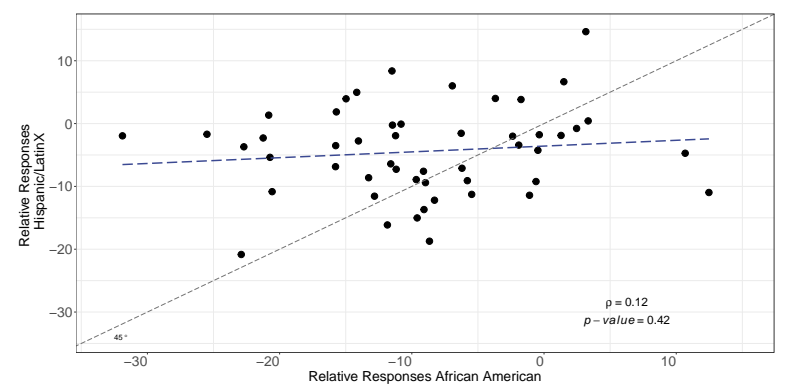

(a) All CBSAs

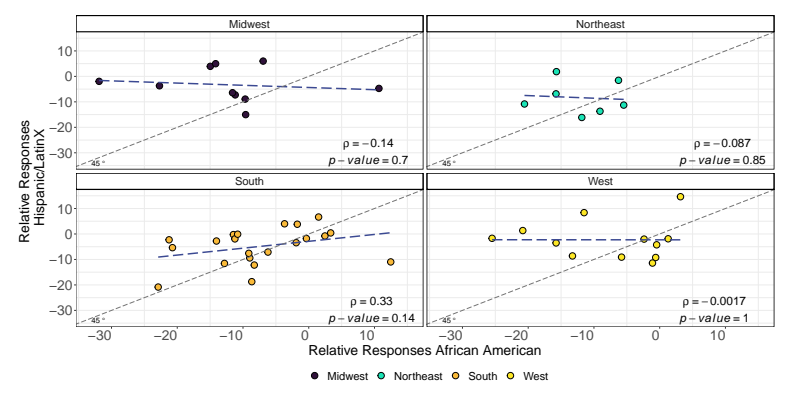

(b) By Census Regions

Note: Figure plots correlations between relative response rate differentials for African American and Hispanic/LatinX identities in all markets (Panel A) and by Census Region (Panel B). The figure includes a dashed line with a fitted linear regression, the Pearson correlation coefficient $(\rho)$, and the $p-$ value that test $\rho=0$. 
Figure SM3.4 plots the correlation between baseline response rates to inquiries from white identities and relative response rate differentials for inquiries from African American identities (Panel A) and Hispanic/LatinX identities (Panel B). We find evidence of negative correlations of -0.2 and -0.22 between the white baseline response rates and discriminatory constraints facing African American and Hispanic/LatinX renters, respectively. These findings indicate that discrimination is greater when baseline white response rates are higher.

Figure SM3.4. Correlation Relative Response Rates and White Response Rates

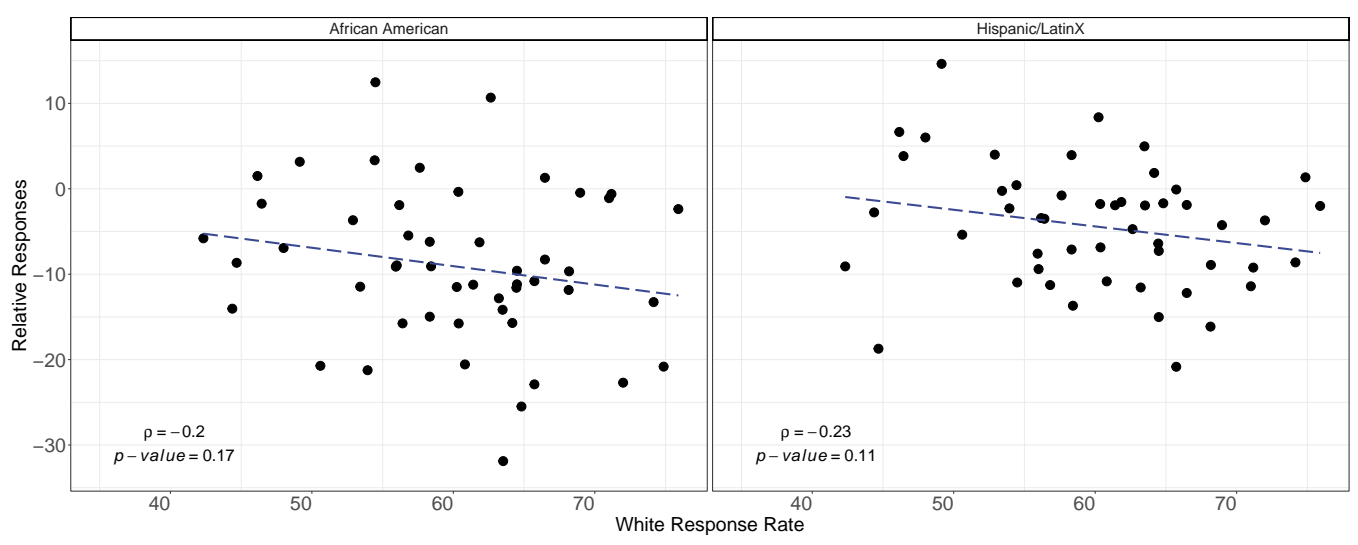

Note: Figure illustrates correlations of baseline response rates to inquiries from white identities and relative response rates to inquiries from African American identities (Panel A) and Hispanic/LatinX identities (Panel B)

Our experimental analysis ran from February 6th 2020 to July 31st 2020, which included the onset of the COVID-19 pandemic and the murder of George Floyd in Minneapolis, MN on May 25th and subsequent protests. We evaluate the generalizability of our estimates by testing for differences in relative response rate differentials before/after city-specific lock-downs and including/omitting the period surrounding the George Floyd homicide and related protests. Table SM3.1 reports relative response rates for each region using trials from: (1) the full study period, (2) excluding the month following the George Floyd homicide, (3) before the beginning of COVID-19 lock-downs, (4) After the COVID-19 lockdowns. Columns 5 and 6 report the pvalues from tests of differences. We do not find any evidence of differences during these weeks, 
aside from differences in relative responses to inquiries sent from Hispanic/LatinX identities in Western markets. 


\section{Table SM3.1. Response Rates by US Regions - George Floyd Homicide and COVID-19}

\begin{tabular}{|c|c|c|c|c|c|c|}
\hline & \multicolumn{6}{|c|}{$\begin{array}{l}\text { Dependent variable: } \\
\text { Response }\end{array}$} \\
\hline & \multirow{2}{*}{$\begin{array}{c}\text { Full } \\
\text { Sample } \\
(1)\end{array}$} & \multirow{2}{*}{$\begin{array}{l}\text { Drop Month After } \\
\text { G. Floyd Homicide } \\
\text { (2) }\end{array}$} & \multicolumn{2}{|c|}{ Lockdowns } & \multirow{2}{*}{$\begin{array}{l}\text { p-value diff. } \\
\text { (1)-(2) } \\
(5) \\
\end{array}$} & \multirow{2}{*}{$\begin{array}{c}p \text {-value diff. } \\
\text { (3)-(4) } \\
\text { (6) } \\
\end{array}$} \\
\hline & & & $\begin{array}{c}\text { Before } \\
\text { (3) }\end{array}$ & $\begin{array}{c}\text { After } \\
(4)\end{array}$ & & \\
\hline \multicolumn{7}{|l|}{ Panel A: Relative Responses } \\
\hline African American $\times$ Midwest & $\begin{array}{c}-0.1231 * * * \\
(0.0251)\end{array}$ & $\begin{array}{c}-0.1225 * * * \\
(0.0288)\end{array}$ & $\begin{array}{l}-0.1168 * * * \\
(0.0325)\end{array}$ & $\begin{array}{c}-0.1257 * * * \\
(0.0334)\end{array}$ & 0.946 & 0.970 \\
\hline African American $\times$ Northeast & $\begin{array}{l}-0.1215 * * * \\
(0.0176)\end{array}$ & $\begin{array}{l}-0.1329 * * * \\
(0.0196)\end{array}$ & $\begin{array}{l}-0.1362 * * * \\
(0.0326)\end{array}$ & $\begin{array}{l}-0.1138 * * * \\
(0.0151)\end{array}$ & 0.294 & 0.176 \\
\hline African American $\times$ South & $\begin{array}{c}-0.0755^{* * *} \\
(0.0159)\end{array}$ & $\begin{array}{c}-0.0808 * * * \\
(0.0168)\end{array}$ & $\begin{array}{c}-0.1021 * * * \\
(0.0261)\end{array}$ & $\begin{array}{c}-0.0599 * * \\
(0.0233)\end{array}$ & 0.291 & 0.165 \\
\hline African American $\times$ West & $\begin{array}{c}-0.0788^{* * * *} \\
(0.0212)\end{array}$ & $\begin{array}{l}-0.0825 * * * \\
(0.0205)\end{array}$ & $\begin{array}{c}-0.0724 * * * \\
(0.0279)\end{array}$ & $\begin{array}{c}-0.0814 * * * \\
(0.0260)\end{array}$ & 0.104 & 0.948 \\
\hline Hispanic/LatinX $\times$ Midwest & $\begin{array}{l}-0.0359^{*} \\
(0.0207)\end{array}$ & $\begin{array}{l}-0.0363^{*} \\
(0.0198)\end{array}$ & $\begin{array}{c}-0.0607 * * * \\
(0.0217)\end{array}$ & $\begin{array}{l}-0.0237 \\
(0.0293)\end{array}$ & 0.897 & 0.263 \\
\hline Hispanic/LatinX $\times$ Northeast & $\begin{array}{c}-0.0813 * * * \\
(0.0278)\end{array}$ & $\begin{array}{l}-0.0895 * * * \\
(0.0306)\end{array}$ & $\begin{array}{c}-0.1074 * * * \\
(0.0345)\end{array}$ & $\begin{array}{c}-0.0686^{* * *} \\
(0.0312)\end{array}$ & 0.849 & 0.125 \\
\hline Hispanic/LatinX $\times$ South & $\begin{array}{c}-0.0516^{* * *} \\
(0.0153)\end{array}$ & $\begin{array}{c}-0.0483 * * * \\
(0.0156)\end{array}$ & $\begin{array}{c}-0.0701 * * * \\
(0.0239)\end{array}$ & $\begin{array}{l}-0.0406^{*} \\
(0.0213)\end{array}$ & 0.397 & 0.279 \\
\hline Hispanic/LatinX $\times$ West & $\begin{array}{l}-0.0260^{*} \\
(0.0157)\end{array}$ & $\begin{array}{l}-0.0116 \\
(0.0179)\end{array}$ & $\begin{array}{c}0.0302 \\
(0.0278) \\
\end{array}$ & $\begin{array}{c}-0.0510^{* *} \\
(0.0201)\end{array}$ & 0.016 & 0.033 \\
\hline \multicolumn{7}{|l|}{ Panel B: Coefficients } \\
\hline African American $\times$ Midwest & $\begin{array}{c}-0.0775^{* * * *} \\
(0.0158)\end{array}$ & $\begin{array}{l}-0.0773 * * * \\
(0.0182)\end{array}$ & $\begin{array}{c}-0.0781 * * * \\
(0.0217)\end{array}$ & $\begin{array}{c}-0.0769 * * * \\
(0.0204)\end{array}$ & 0.946 & 0.970 \\
\hline African American $\times$ Northeast & $\begin{array}{c}-0.0747 * * * \\
(0.0108)\end{array}$ & $\begin{array}{l}-0.0835^{* * * *} \\
(0.0123)\end{array}$ & $\begin{array}{l}-0.0941 * * * \\
(0.0225)\end{array}$ & $\begin{array}{l}-0.0664 * * * \\
(0.0088)\end{array}$ & 0.297 & 0.180 \\
\hline African American $\times$ South & $\begin{array}{l}-0.0422 * * * \\
(0.0089)\end{array}$ & $\begin{array}{l}-0.0461 * * * \\
(0.0096)\end{array}$ & $\begin{array}{c}-0.0626 * * * \\
(0.0160)\end{array}$ & $\begin{array}{c}-0.0318^{* *} \\
(0.0124)\end{array}$ & 0.294 & 0.168 \\
\hline African American $\times$ West & $\begin{array}{c}-0.0511 * * * \\
(0.0137)\end{array}$ & $\begin{array}{l}-0.0544 * * * \\
(0.0135)\end{array}$ & $\begin{array}{c}-0.0513^{* *} \\
(0.0198)\end{array}$ & $\begin{array}{l}-0.0508 * * * \\
(0.0163)\end{array}$ & 0.107 & 0.948 \\
\hline Hispanic/LatinX $\times$ Midwest & $\begin{array}{l}-0.0226^{*} \\
(0.0130)\end{array}$ & $\begin{array}{l}-0.0229 * \\
(0.0125)\end{array}$ & $\begin{array}{l}-0.0406 * * * \\
(0.0145)\end{array}$ & $\begin{array}{l}-0.0145 \\
(0.0179)\end{array}$ & 0.897 & 0.265 \\
\hline Hispanic/LatinX $\times$ Northeast & $\begin{array}{l}-0.0500 * * * \\
(0.0171)\end{array}$ & $\begin{array}{l}-0.0562 * * * \\
(0.0192)\end{array}$ & $\begin{array}{c}-0.0741 * * * \\
(0.0238)\end{array}$ & $\begin{array}{c}-0.0400 * * \\
(0.0182)\end{array}$ & 0.849 & 0.128 \\
\hline Hispanic/LatinX $\times$ South & $\begin{array}{c}-0.0289 * * * \\
(0.0085)\end{array}$ & $\begin{array}{c}-0.0275^{* * * *} \\
(0.0089)\end{array}$ & $\begin{array}{c}-0.0430 * * * \\
(0.0146)\end{array}$ & $\begin{array}{l}-0.0216^{*} \\
(0.0113)\end{array}$ & 0.399 & 0.282 \\
\hline Hispanic/LatinX $\times$ West & $\begin{array}{l}-0.0169 \\
(0.0102)\end{array}$ & $\begin{array}{l}-0.0076 \\
(0.0118)\end{array}$ & $\begin{array}{c}0.0214 \\
(0.0197) \\
\end{array}$ & $\begin{array}{c}-0.0319^{* *} \\
(0.0126)\end{array}$ & 0.018 & 0.035 \\
\hline Mean Response (White) Midwest & 0.63 & 0.63 & 0.67 & 0.61 & & \\
\hline Mean Response (White) Northeast & 0.61 & 0.63 & 0.69 & 0.58 & & \\
\hline Mean Response (White) South & 0.56 & 0.57 & 0.61 & 0.53 & & \\
\hline Mean Response (White) West & 0.65 & 0.66 & 0.71 & 0.62 & & \\
\hline Gender & Yes & Yes & Yes & Yes & & \\
\hline Education Level & Yes & Yes & Yes & Yes & & \\
\hline Inquiry Order & Yes & Yes & Yes & Yes & & \\
\hline Observations & 25,428 & 20,337 & 7,947 & 17,481 & & \\
\hline
\end{tabular}

Notes: Table reports coefficients from a within-property linear regression model including controls for gender, education and order the inquiry was sent. Panel (A) reports relative responses constructed as $R R=\frac{\beta}{\mu}$ where $\mu$ is the average response for white identities. Panel (B) reports the coefficients used to construct the relative responses. The bottom panel shows the average response for white identities. Column (1) reports results for the full sample. Column (2) drops the inquiries sent the month after George Floyd's homicide on May 25th 2020. Column (3) show results for inquiries sent before COVID-19 lock downs were enacted, and column (4) for inquires sent after. Column (5) shows thep-value of a test of differences between the full sample results and the results that exclude the month after May 25th. Column (6) shows the $p$-value of a test of differences between results from before and after lock downs. Standard errors clustered at the CBSA Downtown/Suburb level reported in parentheses.

* Significant at $10 \%$ level, ** significant at $5 \%$ level, *** significant at $1 \%$ level. 
Finally, we designed our analysis to test for differences in discrimination depending upon difference from the city center. Table SM3.2 reports estimates of differences in relative response rates for properties located in downtown vs. suburban zones. We find no evidence of statistical differences in the 50 city sample.

Table SM3.2. Response Rates by Downtown and Suburbs

\begin{tabular}{lc}
\hline \hline & $\begin{array}{c}\text { Dependent variable: } \\
\text { Response }\end{array}$ \\
\cline { 2 - 2 } & $(1)$ \\
\hline African American & $-0.0545^{* * *}$ \\
African American Suburb & $(0.0091)$ \\
Hispanic/LatinX & -0.0033 \\
Hispanic/LatinX Suburb & $(0.0125)$ \\
& $-0.0231^{* * *}$ \\
Mean Response (White) Downtown & $(0.0074)$ \\
Mean Response (White) Suburb & -0.0093 \\
Gender & $(0.0114)$ \\
Education Level & 0.62 \\
Inquiry Order & 0.58 \\
Address FE & Yes \\
\hline Observations & Yes \\
\end{tabular}

Notes: Table reports coefficients from a within-property linear model including controls for gender, education and order the inquiry was sent. Downtown zones were defined as the set of ZIP codes within a CBSA that contains the $5 \%$ of the population nearest to the city center $(25,26)$. ZIP codes that do not belong to Downtown zones were defined as Suburbs. Standard errors clustered at the CBSA Downtown/Suburb level. 


\section{Methods for Analysis of Discrimination and Segregation}

\section{Dissimilarity Indices}

We measure the level of segregation for each group in each housing market using the dissimilarity index developed by Cutler (1999) (30). The dissimilarity measure computes the distribution of African American or Hispanic/LatinX households living in the same census block groups as white households (the reference category), relative to the market-level shares of each group and the market-level shares of white households (the reference category). Table SM4.1 reports the dissimilarity index measure computed for African American and Hispanic/LatinX using the shares of households in all Census block groups in each market, from the 2014-2018 ACS. For African Americans, the dissimilarity index is defined as:

$$
\text { Dissimilarity }=\frac{1}{2} \sum_{i=1}^{n}\left|\frac{A A_{i}}{A A_{\text {total }}}-\frac{W_{i}}{W_{\text {total }}}\right|
$$

where $A A_{i}$ is the number of African American households in census block group (CBG) $i$, and $A A_{\text {total }}$ is the number of African American households in the city, $W_{i}$ is the number of white households in CBG $i$, and $W_{\text {total }}$ is the number of white households in the city. Index values fall in the range between 0 and 1, where lower values indicate a more even distribution of African American and white households within a city. According to Cutler (1999), a dissimilarity index of greater than .6 denotes high segregation, between .3 and .6 moderate segregation and smaller than .3 is considered low segregation. The calculation is analogous for Hispanic/LatinX. 
Table SM4.1. CBSA's Dissimilarity Indices

\begin{tabular}{|c|c|c|}
\hline \multirow[t]{2}{*}{ CBSA } & \multicolumn{2}{|c|}{ Dissimilarity Indices (relative to whites) } \\
\hline & African American & Hispanic/LatinX \\
\hline Atlanta, GA & 0.6192 & 0.5476 \\
\hline Austin, TX & 0.5571 & 0.4521 \\
\hline Baltimore, MD & 0.6727 & 0.5184 \\
\hline Birmingham, AL & 0.6821 & 0.5963 \\
\hline Boston, MA & 0.7086 & 0.6349 \\
\hline Buffalo, NY & 0.7586 & 0.5854 \\
\hline Charlotte, NC & 0.5692 & 0.5457 \\
\hline Chicago, IL & 0.7778 & 0.5888 \\
\hline Cincinnati, $\mathrm{OH}$ & 0.7112 & 0.5756 \\
\hline Cleveland, $\mathrm{OH}$ & 0.7547 & 0.5860 \\
\hline Columbus, $\mathrm{OH}$ & 0.6655 & 0.5601 \\
\hline Dallas, TX & 0.6231 & 0.5457 \\
\hline Denver, CO & 0.6658 & 0.5166 \\
\hline Detroit, MI & 0.7617 & 0.5572 \\
\hline Hartford, CT & 0.7070 & 0.6145 \\
\hline Houston, TX & 0.6442 & 0.5502 \\
\hline Indianapolis, IN & 0.6808 & 0.5690 \\
\hline Jacksonville, FL & 0.5843 & 0.3783 \\
\hline Kansas City, MO & 0.6374 & 0.5270 \\
\hline Las Vegas, NV & 0.4678 & 0.4561 \\
\hline Los Angeles, CA & 0.7036 & 0.6335 \\
\hline Louisville, KY & 0.6287 & 0.5449 \\
\hline Memphis, TN & 0.6375 & 0.6050 \\
\hline Miami, FL & 0.6822 & 0.5873 \\
\hline Milwaukee, WI & 0.8136 & 0.5954 \\
\hline Minneapolis, MN & 0.6271 & 0.5395 \\
\hline Nashville, TN & 0.5812 & 0.5463 \\
\hline New Orleans, LA & 0.6747 & 0.4931 \\
\hline New York, NY & 0.7894 & 0.6310 \\
\hline Oklahoma City, OK & 0.5888 & 0.5336 \\
\hline Orlando, FL & 0.5425 & 0.4418 \\
\hline Philadelphia, PA & 0.7067 & 0.6015 \\
\hline Phoenix, AZ & 0.5781 & 0.5237 \\
\hline Pittsburgh, PA & 0.7020 & 0.5494 \\
\hline Portland, OR & 0.6078 & 0.4308 \\
\hline Providence, RI & 0.6497 & 0.6488 \\
\hline Raleigh, NC & 0.4726 & 0.4706 \\
\hline Richmond, VA & 0.5629 & 0.5574 \\
\hline Riverside, CA & 0.5254 & 0.4466 \\
\hline Sacramento, CA & 0.6164 & 0.4261 \\
\hline Salt Lake City, UT & 0.6473 & 0.4673 \\
\hline San Antonio, TX & 0.5603 & 0.4735 \\
\hline San Diego, CA & 0.5911 & 0.5215 \\
\hline San Francisco, CA & 0.6553 & 0.5329 \\
\hline San Jose, CA & 0.5653 & 0.5257 \\
\hline Seattle, WA & 0.5965 & 0.4450 \\
\hline St. Louis, MO & 0.7461 & 0.5132 \\
\hline Tampa, FL & 0.6092 & 0.4481 \\
\hline Virginia Beach, VA & 0.5349 & 0.4363 \\
\hline Washington, DC & 0.6435 & 0.5337 \\
\hline
\end{tabular}

Notes: Table reports dissimilarity indexes for each of the 50 markets. The indexes were calculated using the 2014-2018 ACS population data at the block group level. 


\section{Methods for Testing for Population-Level Housing Outcomes}

We match our experimental data to recently-available data on renter housing location choices from InfoUSA's (now known as Data Axel) consumer database, which tracks 120 million households and 292 million individuals between 2006-2019, and is maintained using 29 billion records from 100 sources including census statistics, billing statements, telephone directory listings and mail order buyers/magazine subscriptions. Household-level identifiers provide information on the gender, race/ethnicity, age, address, renter/owner status and estimated household income of renters that made a move in 2020.

Using the addresses of rental properties in the experiment and in the InfoUSA data set, we were able to match exactly 5,433 of the $8,476(64.1 \%)$ listings in the experimental sample to properties in the InfoUSA database and obtain information on renter occupants. Table SM5.1 reports the matched percentages by race/ethnic group.

Table SM5.1. Percentage of Experimental Listings Matched to InfoUSA's database by Race/Ethnicity

\begin{tabular}{lcc}
\hline \hline & & \\
Race & Freq. & Percent \\
\hline Af. American & 665 & 12.24 \\
Hispanic/LatinX & 605 & 11.14 \\
Other & 317 & 5.83 \\
White & 3,846 & 70.79 \\
\hline Total & 5,433 & 100 \\
\hline \hline
\end{tabular}

We impute the racial/ethnic identity of each renter in the InfoUSA dataset using the WRU algorithm, which computes the probability of a given name as corresponding to a racial/ethnic group using individuals' surnames and county of location. The algorithm is implemented using a bayesian estimator, trained with the Census Bureau's Surname List and information from geocoded voter registration records $(18,19)$. For each renter observed in the InfoUSA data, we assign the racial/ethnic identity that has the highest probability of affiliation. 


\subsection{Tests of Differential Treatment and Housing Outcomes}

To estimate the relationship between differential treatment identified in the correspondence study and population outcomes in the rental housing market, we estimate the following series of within-listing linear probability models.

\section{All Groups}

Using all groups and the full sample, we estimate the relative probability that the racial/ethnic identity of the renter that inhabits the property is the same as the identity that sends the inquiry:

$$
\text { Same Race }_{i j}=\beta_{R} \text { Response }_{j}+\alpha+\theta X_{j}+\delta_{i}+\epsilon_{i j}
$$

We use coefficients from Eq. 5 to compare these probabilities under the two experimental response conditions. The top panel of Figure 3 plots the estimates from Eq: 6 .

$$
\frac{P(\text { Same Race } \mid \text { Response }=0)}{P(\text { Same Race } \mid \text { Response }=1)}=\frac{\alpha}{\beta_{R}+\alpha}
$$

The dependent variable $S a m e \operatorname{Race}_{i j}(S R)$ takes a value of one if the race/ethnicity of the renter observed to inhabit the property matches the race/ethnicity of experimental identity that sent the inquiry $j$ to listing $i$; and zero otherwise. Response ${ }_{j}$ is an indicator that takes a value of one if the identity received a response. As in all specifications, $X_{j}$ is a vector of identity-specific control variables: gender, education level, and the order in which the inquiry was sent. $\delta_{i}$ is a listing-specific fixed effect that controls for any within listing time-invariant characteristics. Standard errors are obtained using the delta method.

\section{Group-Specific Relationships}

We use coefficients from Eq. 7 to compute differences in these probabilities for renters of color, African American renters, Hispanic/LatinX renters, and white renters. Standard errors are 
obtained using the delta method. For the renters of color group (which combines the samples of African American and Hispanic/LatinX renters), we estimate:

$$
\begin{aligned}
\text { Same Race }_{i j} & =\beta_{M R} \text { Renter of Color }_{j} \times \text { Response }_{j} \\
& +\beta_{M} \text { Renter of Color }_{j} \\
& +\beta_{W R} \text { White }_{j} \times \text { Response }_{j}+\alpha \\
& +\theta X_{j}+\delta_{i}+\epsilon_{i j}
\end{aligned}
$$

The left column in the middle panel of Figure 3 plots the estimates from Eq: 8 and the right column plots the estimates from Eq: 9 ;

$$
\begin{gathered}
\frac{P(\text { Same Race } \mid \text { Renter of Color }=1, \text { Response }=0)}{P(\text { Same Race } \mid \text { Renter of Color }=1, \text { Response }=1)}=\frac{\beta_{M}+\alpha}{\beta_{M R}+\beta_{M}+\alpha} \\
\frac{P(\text { Same Race } \mid \text { White }=1, \text { Response }=0)}{P(\text { Same Race } \mid \text { White }=1, \text { Response }=1)}=\frac{\alpha}{\beta_{W R}+\alpha}
\end{gathered}
$$

The dependent variable $S a m e$ Race $_{i j}(S R)$ takes a value of one if the race/ethnicity of the renter observed to inhabit the property matches the race/ethnicity of experimental identity that sent the inquiry $j$ to listing $i$; and zero otherwise. Renter of Color $(R o C)$ is an indicator variable that takes a value of one if the race group associated with the experimental identity is either African American or Hispanic/LatinX; and zero otherwise. Response ${ }_{j}$ is an indicator that takes a value of one if the identity received a response. As in all specifications, $X_{j}$ is a vector of identityspecific control variables: gender, education level, and the order in which the inquiry was sent. $\delta_{i}$ is a listing-specific fixed effect that controls for any within listing time-invariant characteristics. Standard errors are obtained using the delta method.

For group-specific results for African American and LatinX renters, we estimate: 


$$
\begin{aligned}
\text { Same Race }_{i j} & =\beta_{A R} \text { African American }_{j} \times \text { Response }_{j} \\
& +\beta_{A} \text { African American } \\
& +\beta_{L R} \text { Hispanic/Latin }_{j} \times \text { Response }_{j} \\
& +\beta_{L} \text { Hispanic/LatinX }_{j} \\
& +\beta_{W R} \text { White }_{j} \times \text { Response }_{j}+\alpha \\
& +\theta X_{j}+\delta_{i}+\epsilon_{i j}
\end{aligned}
$$

The middle-left column in the middle panel of Figure 3 plots the estimates from Eq: 11 and the right column plots the estimates from Eq: 12 ,

$$
\begin{aligned}
& \frac{P(\text { Same Race } \mid \text { Af Am }=1, \text { Response }=0)}{P(\text { Same Race } \mid \text { Af Am }=1, \text { Response }=1)}=\frac{\beta_{A}+\alpha}{\beta_{A R}+\beta_{A}+\alpha} \\
& \frac{P(\text { Same Race } \mid \text { Latin } X=1, \text { Response }=0)}{P(\text { Same Race } \mid \text { Latin } X=1, \text { Response }=1)}=\frac{\beta_{L}+\alpha}{\beta_{L R}+\beta_{L}+\alpha}
\end{aligned}
$$

The dependent variable $S a m e$ Race $_{i j}(S R)$ takes one if the race/ethnicity of the renter observed to inhabit the property matches the race/ethnicity of experimental identity that sent the inquiry $j$ to listing $i$; and zero otherwise. Renter of Color $(\operatorname{RoC})$ is an indicator variable that takes a value of one if the race group associated with the experimental identity is either African Ameri-

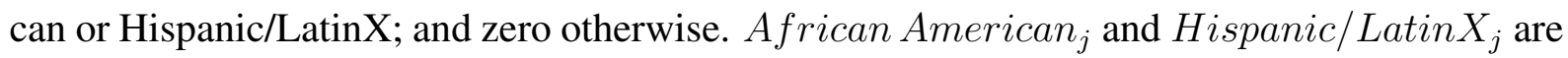
also indicator variables that take a value of one if the race group associated with the experimental identity is either African American or Hispanic/LatinX; and zero otherwise. Response ${ }_{j}$ is an indicator that takes a value of one if the identity received a response. As in all specifications, $X_{j}$ is a vector of identity-specific control variables: gender, education level, and the order in which the inquiry was sent. $\delta_{i}$ is a listing-specific fixed effect that controls for any within listing time-invariant characteristics. Standard errors are obtained using the delta method. 
All estimates from equations (5), (7), and (10) are reported in Table ??:

Table SM5.2. Estimates of Baseline Renter Outcomes

\begin{tabular}{|c|c|c|c|}
\hline & \multicolumn{3}{|c|}{ Dependent variable: Same Race } \\
\hline & (1) & (2) & (3) \\
\hline Received a Response & $\begin{array}{c}0.0917 * * * \\
(0.0140)\end{array}$ & & \\
\hline Renter of Color $\times$ Response & & $\begin{array}{l}0.0219 * \\
(0.0124)\end{array}$ & \\
\hline Renter of Color & & $\begin{array}{c}-0.5774 * * * \\
(0.0275)\end{array}$ & \\
\hline White $\times$ Response & & $\begin{array}{c}0.0433 * * \\
(0.0196)\end{array}$ & $\begin{array}{c}0.0437 * * \\
(0.0195)\end{array}$ \\
\hline African American $\times$ Response & & & $\begin{array}{l}0.0265^{*} \\
(0.0159)\end{array}$ \\
\hline Hispanic/LatinX $\times$ Response & & & $\begin{array}{c}0.0189 \\
(0.0159)\end{array}$ \\
\hline African American & & & $\begin{array}{c}-0.5737 * * * \\
(0.0300)\end{array}$ \\
\hline Hispanic/LatinX & & & $\begin{array}{c}-0.5813 * * * \\
(0.0309)\end{array}$ \\
\hline Constant & $\begin{array}{c}0.2614 * * * \\
(0.0081)\end{array}$ & $\begin{array}{c}0.6820 * * * \\
(0.0205)\end{array}$ & $\begin{array}{c}0.6817 * * * \\
(0.0206)\end{array}$ \\
\hline Gender & Yes & Yes & Yes \\
\hline Education Level & Yes & Yes & Yes \\
\hline Inquiry Order & Yes & Yes & Yes \\
\hline Observations & 16,299 & 16,299 & 16,299 \\
\hline
\end{tabular}

Notes: Table reports coefficients from a within-property linear regression model including controls for gender, education and inquiry order.

* Significant at $10 \%$ level, ** significant at 5\% level, *** significant at $1 \%$ level.

The full sample results from the top panel of Figure 3 are not guaranteed to fall within the range of the group-specific results. We note that the $P($ Same Race $\mid$ Response $=0)$ estimated in 
Table SM5.2 column (1) is the weighted average (approximately) of the coefficients in column (2) these weights are the in sample relative sizes of each group, where:

$$
\begin{aligned}
P(\text { Same Race } \mid \text { Response }=0) & =w_{0} * P(S R \mid \text { RoC }=1, \text { Resp }=0) \\
& +\left(1-w_{0}\right) * P(S R \mid \text { RoC }=0, \text { Resp }=0) \\
P(\text { Same Race } \mid \text { Response }=1) & =w_{1} * P(S R \mid \operatorname{RoC}=1, \text { Resp }=1) \\
& +\left(1-w_{1}\right) * P(S R \mid \operatorname{RoC}=0, \text { Resp }=1)
\end{aligned}
$$

The ratio of the expressions in the LHS is not a simple weighted average of those in the RHS. Note the following:

$$
\begin{aligned}
& \frac{P(\text { Same Race } \mid \text { Response }=0)}{P(\text { Same Race } \mid \text { Response }=1)}= \\
& =\frac{w_{0} * P(S R \mid R o C=1, \operatorname{Resp}=0)+\left(1-w_{0}\right) * P(\text { Same Race } \mid \operatorname{RoC}=0, \operatorname{Resp}=0)}{w_{1} * P(S R \mid \operatorname{RoC}=1, \operatorname{Resp}=1)+\left(1-w_{1}\right) * P(S R \mid \operatorname{RoC}=0, \operatorname{Resp}=1)} \\
& =\frac{P(S R \mid R o C=1, \operatorname{Resp}=0)}{P(S R \mid \operatorname{RoC}=1, \operatorname{Resp}=1)}\left\{\frac{w_{0}}{\left[w_{1} *+\left(1-w_{1}\right)\left(\frac{P(S R \mid \operatorname{RoC}=0, \operatorname{Resp}=1)}{P(S R \mid \operatorname{RoC}=1, \operatorname{Res} p=1)}\right)\right]}\right\} \\
& +\frac{P(S R \mid R o C=0, \operatorname{Resp}=0)}{P(S R \mid R o C=0, \operatorname{Resp}=1)}\left\{\frac{\left(1-w_{0}\right)}{\left[w_{1} *\left(\frac{P(S R \mid \operatorname{RoC}=1, \operatorname{Resp}=1)}{P(\text { SR } \mid \text { RoC }=0, \text { Resp }=1)}\right)+\left(1-w_{1}\right)\right]}\right\}
\end{aligned}
$$

The weights depend on the relative in sample group sized and also on the ratio of response probabilities between the each of the renter of color identities and the white identities. The ratio for the separate groups is analogous. 